\title{
A new High-Throughput-Screening-assay for Photoantimicrobials Based on EUCAST Revealed Photoantimicrobials in Cortinariaceae
}

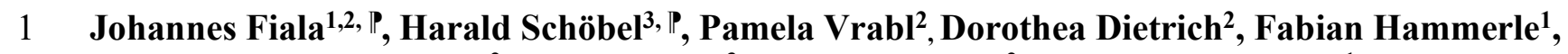

2 Desirée Josefine Altmann², Ronald Stärz ${ }^{3}$, Ursula Peintner ${ }^{2}$, and Bianka Siewert ${ }^{1 *}$

$3 \quad{ }^{1}$ Department of Pharmacognosy, Institute of Pharmacy, University of Innsbruck, Innsbruck, Austria

$4 \quad{ }^{2}$ Institute of Microbiology, University of Innsbruck, Innsbruck, Austria

$5{ }^{3}$ Department of Biotechnology, MCI Management Center Innsbruck, Maximilianstraße 2, Innsbruck,

$6 \quad 6020$ Austria

$7 \quad$ These authors contributed equally.

8 * Correspondence:

9 Bianka.siewert@uibk.ac.at

10 Keywords: Photoantimicrobials, PACT, EUCAST, Cortinariaceae, Anthraquinone, LED-technique

11 Abstract

12 A spark of light might unravel antimicrobial activity of colored compounds, which otherwise would

13 have been classified as inactive. While many mushrooms contain such colorful pigments but lack

14 antimicrobial activity, we wondered if a controlled irradiation is needed to unleash their effect. To

15 explore such photoantimicrobial actions in the Kingdom Fungi, an efficient high-throughput-screening

16 (HTS) assay is needed. Here we report on the establishment of a reliable photoantimicrobial assay

17 based on the EUCAST recommendations, which was validated with known photosensitzers (i.e.,

18 curcumin, phenalenone, rose bengal, an hypericum extract, and methylene blue). Furthermore, an

19 improved LED-irradiation setup enabling with only 24 LEDs a homogenous irradiation of a 96-well

20 plate is presented. The established HTS-assay was utilized to screen six colorful Cortinarius extracts

21 unrevealing C. xanthophyllus and C. rufo-olivaceus as promising sources for new photoantimicrobials.

Whenever microorganisms share the same ecological niche - as for example soil fungi and soil bacteria - an orchestra of chemical compounds evolves reaching from mediators of stimulative symbiosis to detrimental antibiosis (Frey-Klett et al., 2011; Deveau et al., 2018). Plenty of such natural products have commercial values, especially as pharmaceuticals (Hyde et al., 2019). For example, most antibiotics approved by the Food and Drug Administration (FDA) are natural products (Lewis, 2020) and belong to antibiosis, which is described as chemical warfare.

According to Künzler (2018), fungal cells usually defend themselves by rather secreting chemical effectors against microbial competitors, than by storing them intracellular (Künzler, 2018). Nevertheless, fruiting bodies - or more precisely the hyphae differentiating into fruit-body tissues often contain promising antibiotics. For example, various antimicrobial triterpenoids were isolated from the fruiting bodies of polypores, especially of Ganoderma spp. (Dresch et al., 2015; Basnet et al., 2017). These observations are rather the rule than the exception, because for most basidiomycete 


\section{A new High-Throughput-Screening-assay for Photoantimicrobials}

genera an antimicrobial activity was found in extracts from the fruiting bodies. Just for a few genera, for example Cortinarius, antimicrobial activities were infrequently described. This, however, contrasts with the observation that fruiting bodies of this genus are rarely infested by other microorganisms (Moser, 1972). Thus, we were wondering whether an important co-factor was missing in the common screening attempts.

Co-factors, which can influence the antimicrobial activity of a secondary metabolite, might be metals (Lachowicz et al., 2020), pH-conditions (Lee et al., 1997; Wiegand et al., 2015), or just a spark of light (Wozniak and Grinholc, 2018; Dos Santos et al., 2019). Such light-activated defense strategies (Downum, 1992; Flors and Nonell, 2006) are well-known for members of the kingdom Plantae and were recently suggested to be also present in fungi (Siewert and Stuppner, 2019; Siewert et al., 2019; Siewert, 2021). Furthermore, light-activated natural compounds are promising pharmaceuticals (Hudson and Towers, 1991; Berenbaum, 1995; Siewert and Stuppner, 2019).

As part of a putative light-activated defense system, the first photosensitizers, i.e. light-activated chemical compounds, were recently activity-guided discovered in fruiting bodies of macromycota (Siewert et al., 2019; Hammerle et al., 2020). Light-activated antimicrobial effects of basidiomycetes are, however, not described yet, despite promising hints (Siewert, 2021). The lack of described photoantimicrobials might be the consequence of a non-existing photo-antimicrobial high-throughput screening (HTS) assay.

In general, plenty of different antimicrobial susceptibility tests are available determining the minimal inhibitory activity (MIC) of a substance. The utilized techniques reach from diffusion over thin-layer chromatography to dilution methods (Balouiri et al., 2016). In recent years, two standard protocols one published by the Clinical and Laboratory Standards Institute (Weinstein and Lewis, 2020) and the other by the European Committee on Antimicrobial Susceptibility Testing (EUCAST (Microbiology and Diseases, 2003)) - were established. Most promising for a HTS assays are such microbroth-dilution assays, which are based on visual (CLSI) or spectrophotometric (EUCAST) turbidity measurements (Wiegand et al., 2008). Microbroth-dilution assays can be conducted in 96 well-plates and thus allow a high throughput: Eight antibiotics can be tested in ten different concentrations on one plate in the dark, including the sterility and growth controls (Wiegand et al., 2008).

The crucial part of every PhotoMIC assay is the irradiation. Nowadays, dental curing lights (Nielsen et al., 2015) or handmade LED setups (Morici et al., 2020) replaced previously used light bulbs and lasers (Calin and Parasca, 2009). Dental lights - originally designed to polymerize composite fillings - allow only single irradiation, and therefore limit the throughput. Described LED-setups (not limited to microbials) vary from a single-emitter LED (Ogonowska et al., 2019) over 24 (Quintanar et al., 2016) and 96 LEDs (Butler et al., 2010; Chen et al., 2012; Hopkins et al., 2016; Katz et al., 2018) to 195 (Bajgar et al., 2020) or even 432 diodes (Pieslinger et al., 2006). A drawback of all settings with less than 100 diodes, is the missing homogenous light-distribution throughout a 96-well plate (Chen et al., 2012; Hopkins et al., 2016; Quintanar et al., 2016; Ogonowska et al., 2019). Consequently, only parts of a 96-well plate can be used. Common to all multi-diodes settings is the equidistant arrangement of the diodes along the printed circuit board. Taking the nature of light into account, however, we wondered whether an asymmetric positioning of the diodes might improve the all-over distribution of light. Having extrapolated simulations for single LEDs in mind, we hypothesized that a homogenous illumination with only 24 diodes is possible.

Here we will report on (1) the design of a modular, 24 LEDs based irradiation setup for 96-well plates, (2) the establishment of a HTS-PhotoMic assay which was validated with five standard 


\section{A new High-Throughput-Screening-assay for Photoantimicrobials}

photosensitizers (PS, curcumin, phenalenone, rose bengal, and hypericin) and five irradiation wavelengths $(\lambda=428,478,523,598$, and $640 \mathrm{~nm})$; And, (3) the results of a sample set existing out of six Cortinarius extracts and identifying the basidiomycete Cortinarius xanthophyllus and C. rufoolivaceus as species containing photoantimicrobial(s) active against Staphylococcus aureus and Candida albicans.

\section{Materials and Methods}

\subsection{Optical simulations, irradiation setup, and light measurements}

The irradiation system is based on LED-technology. To achieve uniform irradiance along the entire sample, the arrangement of the individual LEDs within the $6 \times 4$ LED array is crucial. Therefore, the LED positions were optimized and verified with optical simulations. The simulation is based on an optical model for single LEDs (Wood, 1994) and is modified to calculate irradiance distribution in terms of Cartesian coordinates (Moreno et al., 2006). To simulate the irradiance $E(x, y, z)$ at any point of the $x, y$-plane at a working distance $z$, the $6 \times 4$ LED array is modeled as

$$
E(x, y, z)=\sum_{n=1}^{6} \sum_{m=1}^{4} \frac{z^{k} \cdot I_{0}}{\left[\left(x-x_{n}\right)^{2}+\left(y-y_{m}\right)^{2}+z^{2}\right]^{\frac{k+2}{2}}}
$$

where $x_{n}$ and $y_{m}$ are the positions of the individual LEDs in meters and $I_{0}$ is the radiant intensity in watt per steradian. The deviation of the manufactured LED from a perfect Lambertian emitter is considered with the correction factor $k$, which depends on the viewing angle $\theta_{1 / 2}$

$$
k=-\frac{\ln 2}{\ln \cos \theta_{1 / 2}} .
$$

The viewing angle $\theta_{1 / 2}$ is the off-axis angle from the LED centerline where the radiant intensity is half of the peak value and is provided by the LED manufacturer. By varying the individual LED positions $x_{m}$ and $y_{m}$, the irradiance distribution in the sample plane can be modified. To achieve a uniform irradiance distribution, the individual LED positions were optimized by a nonlinear least-square curve fitting method with constraints (Betts, 1976; Coleman and Li, 1994; 1996). Optical simulations and optimization were performed using MATLAB R2019b.

All irradiation experiments were carried out with a specially developed irradiation device (SciLED, MCI, Innsbruck) based on LED technology (Figure 1, left). The device consists of an extendable sample holder, where the 96-well plates can be inserted and reproducible positioned in the irradiated area. If the experimental design requires alternative culture plates, e. g. petri dishes, the sample holder can be easily adapted. To ensure a versatile area of application, the device has a modular design. Depending on the demanded irradiation conditions, the LED modular units (Figure 1, insert) can be exchanged. The LED modules were assembled with Luxeon CZ Color Line LEDs (B.V., 2019). Each module consists of 24 LEDs of the same color (nominal peak wavelength). For this work, LEDs of the color violet $(\lambda=420-430 \mathrm{~nm})$, blue $(\lambda=465-475 \mathrm{~nm})$, green $(\lambda=520-540 \mathrm{~nm})$, amber $(\lambda=585-$ $600 \mathrm{~nm})$, and red $(\lambda=624-634 \mathrm{~nm})$ were used. The arrangement of the LEDs in the array was optimized to ensure a uniform irradiance. Figure 1 (right) shows the simulation of the irradiance of one LED modular unit. Next to the wavelength, the radiant exposure can be adjusted by a timer and an intensity controller. 


\section{A new High-Throughput-Screening-assay for Photoantimicrobials}

Light measurements were conducted to characterize the illumination device. To check the uniformity, irradiance was measured using a radiometer and a chemical actinometer (i.e., ferrioxalate). Irradiance measurements were carried out along a $17 \mathrm{~mm} \times 17 \mathrm{~mm}$ grid using the radiometer PM100D and the photodiode power sensor S120 VC with a measurement uncertainty of $\pm 3 \%(\lambda=440-980 \mathrm{~nm})$ and $\pm 5 \%(\lambda=280-439 \mathrm{~nm})$ (Thorlabs). The ferrioxalate actinometer $\left(\mathrm{K}_{3}\left[\mathrm{Fe}\left(\mathrm{C}_{2} \mathrm{O}_{3}\right)_{3}\right]\right)$ and phenanthroline-based developing solutions were made using previously published methods (Hopkins et al., 2016). Spectral measurements were performed using the spectrometer MAYA 2000 Pro equipped with diffraction grating \#HC-1 and entrance slit of $5 \mu \mathrm{m}$ (Ocean Insights), resulting in a spectral resolution of $0.66 \mathrm{~nm}$ FWHM. Light was coupled into the spectrometer via an optical fiber with a core diameter of $600 \mu \mathrm{m}$ (QP600-1-SR-BX, Ocean Insights) and a cosine corrector (CC-3-UV-S, Ocean Insights). The spectrometer was calibrated with a wavelength calibration source (mercury-argon HG2, Ocean Insights). To characterize the spectral power distribution, the peak shape was modeled with a sum of Gaussian functions (Reifegerste and Lienig, 2008; Supronowicz and Fryc, 2019). By fitting the sum of Gaussian functions to the spectral data, the wavelength where the intensity maximum occurs (peak wavelength in $\mathrm{nm}$ ), the full width at half of the intensity maximum (FWHM in nm), and the full width at ten percent of the intensity maximum ( $\mathrm{FW} 0.1 \cdot I_{\max }$ in $\mathrm{nm}$ ) were calculated.

To evaluate the uniformity, the arithmetic mean irradiance $E_{m}$, the standard deviation $S D$ and the coefficient of variation $c v$ were calculated. As the uniformity was simulated and measured using a radiometer and a chemical actinometer, a comparison with the dimensionless parameter $c v$ is convincing. The coefficient of variation is calculated as the ratio of the standard deviation and the arithmetic mean. Ensuring a precise representation of the spectral data by the model with Gaussian functions, the fit was accepted with a coefficient of determination $R^{2}$ larger than 0.999 .
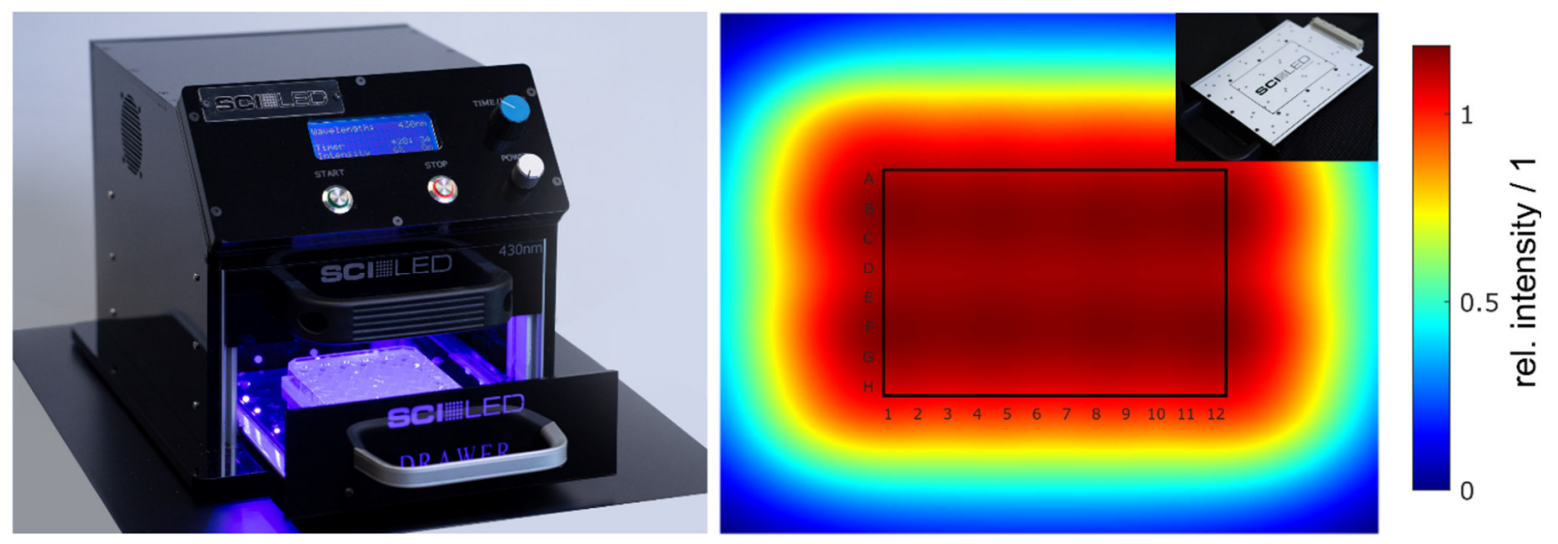

Figure 1: (Color online) Irradiation Setup (SciLED) and simulated irradiance. The irradiation experiments were performed with a LED-based setup (left). Due to its design, the LED modules can be easily exchanged to enable different wavelength settings (insert, top right). With the integrated user interface, the radiant exposure can be set by a timer and an intensity controller. The arrangement of the $6 \times 4$ LED array on the modules was optimized to achieve a uniform irradiance at the sample plane. Optical simulations of the irradiance show a uniform distribution with a theoretical variation of less than $0.1 \%$ over the entire area of a 96-well plates (right). 


\section{A new High-Throughput-Screening-assay for Photoantimicrobials}

\subsection{Mycochemical Part - Reagents, Instruments, and Methods}

All solvents for the extraction and isolation processes were purchased from VWR International (Vienna, Austria). Acetone was distilled prior to use. Solvents for HPLC experiments had pro analysis (p.a.) quality and were obtained from Merck (Merck KGaA, Darmstadt, Germany). Ultrapure water was obtained with the Sartorius arium ${ }^{\circledR} 611$ UV purification system (Sartorius AG, Göttingen, Germany).

Desiccation of the collected fungi was achieved with a dörrex ${ }^{\circledR}$ drying-apparatus from Stöckli (A. \& J. Stöckli AG, Switzerland) operated at a temperature of $50^{\circ} \mathrm{C}$. The fungal biomaterial was milled with a Bosch rotating coffee grinder MKM 6003 (Stuttgart, Germany). The samples were weight with scales from KERN ALS 220-4 (KERN \& SOHN GmbH, Balingen-Frommern, Germany) and Sartorius Cubis ${ }^{\circledR}$-series (Sartorius AG, Göttingen, Germany). During the extraction process, the ultrasonic bathes Sonorex RK 106, Sonorex RK 52, and Sonorex TK 52 (BANDELIN electronic GmbH \& Co. KG, Berlin, Germany) were utilized. Vortexing was done with a Vortex-Genie 2 mixer (Scientific Industries, Inc., Bohemia, New York). For centrifugation, an Eppendorf 5804R centrifuge with a F45-30-11 - 30 place fixed angle rotor (Hamburg, Germany) was used.

HPLC measurements were carried out with the modular system Agilent Technologies 1260 Infinity II with a quaternary pump, vial sampler, column thermostat, diode-array detector, and mass spectrometer. Moreover, the HPLC-system Agilent Technologies 1200 Series with a binary pump, autosampler, column thermostat, and diode-array detector was used. HPLC-systems were purchased from Agilent Technologies, Inc. (Santa Clara, USA). For all HPLC measurements, a Synergi 4u MAX-RP 80A 150 $\mathrm{x} 4,60 \mathrm{~mm}$ column was used. HPLC-DAD-ESI-MS analysis was carried out with the modular system Agilent Technologies 1260 Infinity II equipped with a quaternary pump, vial sampler, column thermostat, diode-array detector, and an ion trap mass spectrometer (amaZon, Bruker, Bremen, Germany).

Pipetting was done with pipettes and tips from Eppendorf AG (Hamburg, Germany) and STARLAB International GmbH (Hamburg, Germany). Reagent reservoirs were obtained from Thermo Fischer Scientific (Waltham, Massachusetts, USA).

\subsection{Mycochemical Part}

\subsubsection{Preparation of fungal extracts}

The fungal biomaterial was dried on a desiccator $\left(\mathrm{T} \sim 50^{\circ} \mathrm{C}\right)$ right after collection (see Table $\mathrm{S} 1$ ) and stored at room temperature until further use $\left(\mathrm{T}=23.0^{\circ} \mathrm{C}\right.$, humidity $\left.=20+/-5 \%\right)$. The biomaterials were milled and sieved utilizing a mesh with the size of $400 \mu \mathrm{m}$. The extraction process was performed under light exclusion at room temperature. The powdered materials $(\mathrm{m}=2.00 \mathrm{~g})$ were extracted with acidified acetone $(\mathrm{V}=20 \mathrm{ml}, 0.1 \mathrm{v} / \mathrm{v} \% 2 \mathrm{~N} \mathrm{HCl})$ in an ultrasonic bath $(\mathrm{t}=10 \mathrm{~min})$. After centrifugation $\left(\mathrm{t}=10 \mathrm{~min}, \mathrm{~T}=4^{\circ} \mathrm{C}, \mathrm{F}=20817 \mathrm{~g}\right)$, acetone was decanted and filtered through cotton wool. The fungal material was extracted twice more with acidified acetone $(\mathrm{V}=5 \mathrm{ml})$. After centrifugation, the supernatant was collected, evaporated, and stored in brown glass vials at room temperature (see Table 1 for yields).

\subsubsection{Reagents, Instruments, and Methods}

Curcumin, dimethylsulfoxid (DMSO), lysogeny broth (LB) agar, phenalenone, and RPMI1640 medium were received from Merck KGaA (Darmstadt, Germany). Potato dextrose agar (PDA) and Mueller Hinton Broth (MHB) were purchased from VWR International (Vienna, Austria). Rose Bengal 


\section{A new High-Throughput-Screening-assay for Photoantimicrobials}

(RB) was received from TCI Europe (Zwijndrecht, Belgium). Hypericum perforatum extract (ethanol) was prepared from the pharmaceutical drug "Johanniskraut $600 \mathrm{mg}$ forte" by Apomedica (Graz, Austria). The 96-well plates (flat bottom) were bought from Sarstedt (Nümbrecht, Germany).

The U-2001 spectrophotometer for adjusting the McFarland standard was from Hitachi (Chiyoda, Japan). For measurement of the 96-well plates, a Tecan Sunrise Remote Plate Reader was used (Männedorf, Switzerland). The adjustment of $\mathrm{pH}$-values was carried out with the $\mathrm{pH}$-meter Mettler Toledo SevenMulti (Mettler-Toledo GmbH, Vienna, Austria).

Pipetting was done with pipettes and tips from Eppendorf AG (Hamburg, Germany) and STARLAB International GmbH (Hamburg, Germany). Reagent reservoirs were obtained from Thermo Fischer Scientific (Waltham, Massachusetts, USA).

\subsubsection{Strains and Cultivation}

All experiments on photodynamic inhibition (PDI) of growth of microorganisms (MOs) and the preparations were carried out under aseptic conditions in a laminar airflow cabinet at room temperature. The test strains used in this study were Candida albicans (501670), Escherichia coli (DSM1103), and Staphylococcus aureus (DSM1104). The strains were reactivated from frozen state and prepared according to manufacturer's recommendations (https://www.dsmz.de/). Until further use, bacterial cultures were stored in darkness at $4^{\circ} \mathrm{C}$ on lysogeny broth agar. C. albicans was cultivated on potato dextrose agar under the same conditions.

For the PDI experiments, the stored cultures were reactivated, and an overnight culture was incubated $\left(\mathrm{T}=37^{\circ} \mathrm{C}, \mathrm{t}=24 \mathrm{~h}\right.$, dark conditions). The bacterial culture inoculum was prepared using a spectrophotometer measurement at $\lambda=600 \mathrm{~nm}$. Turbidity was adjusted to a McFarland standard of 0.5 to prepare a standard suspension of $1.5 \times 10^{8}$ colony forming units $(\mathrm{CFU}) / \mathrm{ml}$. For yeast suspensions, turbidity was measured at $\lambda=530 \mathrm{~nm}$. Liquid media used for PDI experiments were MHB for bacteria and RPMI-1640 (double strength) for yeast.

\subsubsection{PhotoMIC Assay}

For the PDI experiments, flat-bottom 96-well plates were used. On each plate, an extract test section, growth control, fraction-blank, medium-blank, and sterility controls were set up (Figure 2). In the test section three concentrations of fungal extracts (i.e., $\mathrm{c}=25 \mu \mathrm{g} / \mathrm{mL}, 50 \mu \mathrm{g} / \mathrm{mL}$, and $75 \mu \mathrm{g} / \mathrm{mL}$ ), were tested. If needed, smaller or larger concentrations were tested as well. Further, positive controls (dark condition) were established for each experiment: Curcumin (c $=30 \mu \mathrm{g} / \mathrm{mL}, 81.5 \mu \mathrm{M})$ for C. albicans, phenalenone $(\mathrm{c}=75 \mu \mathrm{g} / \mathrm{mL}, 416.2 \mu \mathrm{M})$ for E. coli, and phenalenone $(\mathrm{c}=25 \mu \mathrm{g} / \mathrm{mL}, 138.7 \mu \mathrm{M})$ for S. aureus.

Positive controls, fungal extracts (FE), and growth control were inoculated with an inoculum $(\mathrm{V}=50 \mu \mathrm{l})$ of the test strains within $\mathrm{t}=30 \mathrm{~min}$ after the turbidity adjustment. Two identical 96-well plates were prepared for both dark and light treatment. After ten or sixty minutes of preincubation time in darkness, one plate was irradiated with the SciLED panel at $\lambda=470 \mathrm{~nm}$ for $\mathrm{t}=19 \min 8 \mathrm{sec}$, corresponding to a light dose of $H=9.3 \mathrm{~J} / \mathrm{cm}^{2}$. An alternative irradiation setup was $\mathrm{t}=61 \mathrm{~min} 44 \mathrm{sec}$, corresponding to a light dose of $H=30 \mathrm{~J} / \mathrm{cm}^{2}$. The other plate was kept in the darkness at room temperature. 


\section{A new High-Throughput-Screening-assay for Photoantimicrobials}

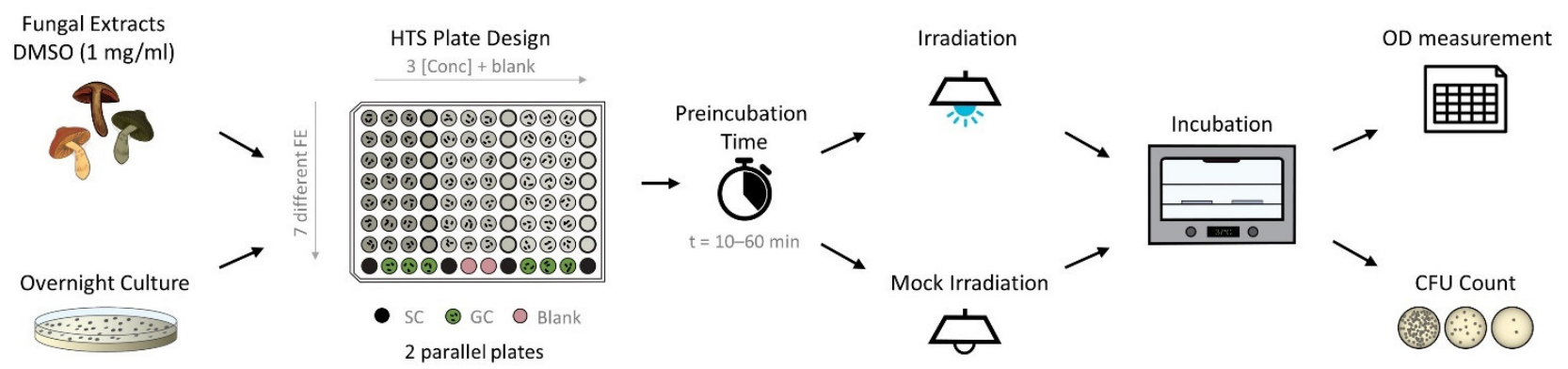

Figure 2. Flow chart of photo-antimicrobial HTS based on the microdilution method. The pipetting scheme represents the fast screening approach of extracts. Up to seven different fungal extracts with three concentrations each are tested on one plate. SC... sterility control, GC... growth control

After (mock)irradiation, the plates were submitted to turbidity measurements. Here, a plate reader was used and before measuring the optical density (bacteria: $\lambda=600 \mathrm{~nm}$, fungi: $\lambda=530 \mathrm{~nm}$ ), the plates were shaken for five seconds. Viability controls were drawn from the control vials and plated on LB/PDA agar. Afterwards, the 96-well plates and LB/PDA agar plates were incubated at $\mathrm{T}=37^{\circ} \mathrm{C}$ in the dark for 24 hours. A second measurement of turbidity was done, followed by taking samples of wells that showed inhibition ( $>20 \%$ ) of population growth control.

Assessment of the PDI experiment was done by correlating the treated well to the uninhibited growth control. Turbidity of fraction-blank and medium-blank was subtracted from corresponding wells to eliminate deviation caused by darkening or bleaching of media and extracts. Each concentration of fungal extracts, the positive control, and the growth control were measured at least in triplicates.

\subsection{Singlet-Oxygen Detection via the DMA-Assay}

To analyze the ability of the six fungal extracts (FE) to generate singlet oxygen after irradiation, the previously described dimethyl anthracene (DMA) assay and a previously characterized irradiation setup were employed (Siewert et al., 2019). As a first step, a DMA solution in ethanol $(\mathrm{c}=1.4 \mathrm{mM})$ (L1) and a L-ascorbic acid-solution in ultrapure water $(\mathrm{c}=100 \mathrm{mM}, \mathrm{pH}=7.0-7.4)$ (L2) were prepared. The fungal extracts were dissolved in DMSO $(\mathrm{c}=1 \mathrm{mg} / \mathrm{mL}, \mathrm{FE})$ and subsequently mixed with the stock solutions (L1 and L2) as well as pure ethanol (L3) to obtain four test-solutions (V =10 $\mu \mathrm{L} \mathrm{FE} \mathrm{+}$ $190 \mu \mathrm{L}$ test-solution): (1) a pure ethanolic solution of the FE to observe photochemical changes of the extract due to the irradiation, (2) a mix with DMA to detect singlet oxygen, (3) a mix with DMA and the antioxidant L-ascorbic acid to prove that singlet oxygen caused the oxidation of DMA, and (4) a control consisting of an ethanolic solution of the extract and L-ascorbic acid to control, that no undesired reaction occurs. DMSO $(\mathrm{V}=10 \mu \mathrm{L})$ was used as negative control, berberine $(\mathrm{c}=1 \mathrm{mg} / \mathrm{mL}$, $2.97 \mathrm{mM}$, DMSO, $\mathrm{V}=10 \mu \mathrm{L})$ and $\mathrm{RB}(\mathrm{c}=0.1 \mathrm{mg} / \mathrm{mL}, 0.10 \mathrm{mM}$, DMSO, $\mathrm{V}=10 \mu \mathrm{L})$ were used as positive controls. Thereafter, optical densities at the wavelengths $\lambda=377 \mathrm{~nm}, 468 \mathrm{~nm}$, and $519 \mathrm{~nm}$ were measured with a plate reader $(t=0 \mathrm{~min})$, followed by four cycles of blue light $(\lambda=468 \mathrm{~nm}, 1.24$ $\mathrm{J} \mathrm{cm}^{-2} \mathrm{~min}^{-1}$, berberine $=$ positive control $)$ or of green light irradiation $\left(\lambda=519 \mathrm{~nm}, 0.92 \mathrm{~J} \mathrm{~cm}^{-2} \mathrm{~min}^{-1}\right.$, rose bengal = positive control). All measurements were done as technical duplicates. The results of the DMA-assay were presented as the mean \pm standard error. Differences between the relative singlet oxygen formation values were statistically evaluated using one-way ANOVA followed by the Bonferroni post-test, and $\mathrm{p}<0.05$ was considered to the significant. 


\section{$3 \quad$ Results}

\subsection{Uniform irradiance and irradiation conditions}

A

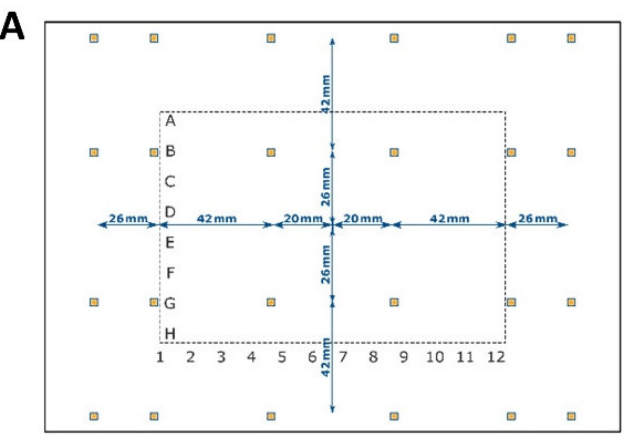

C

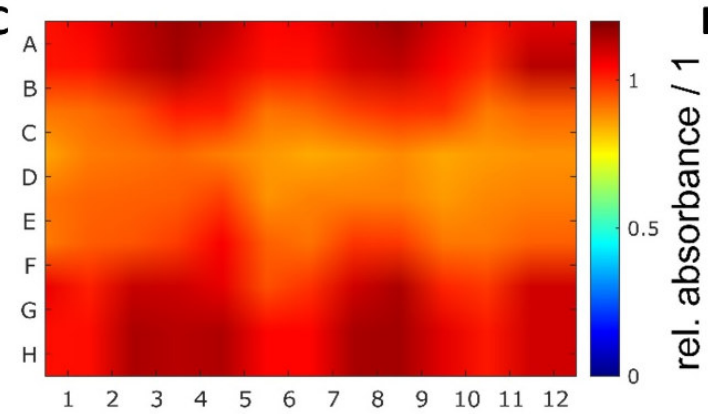

B
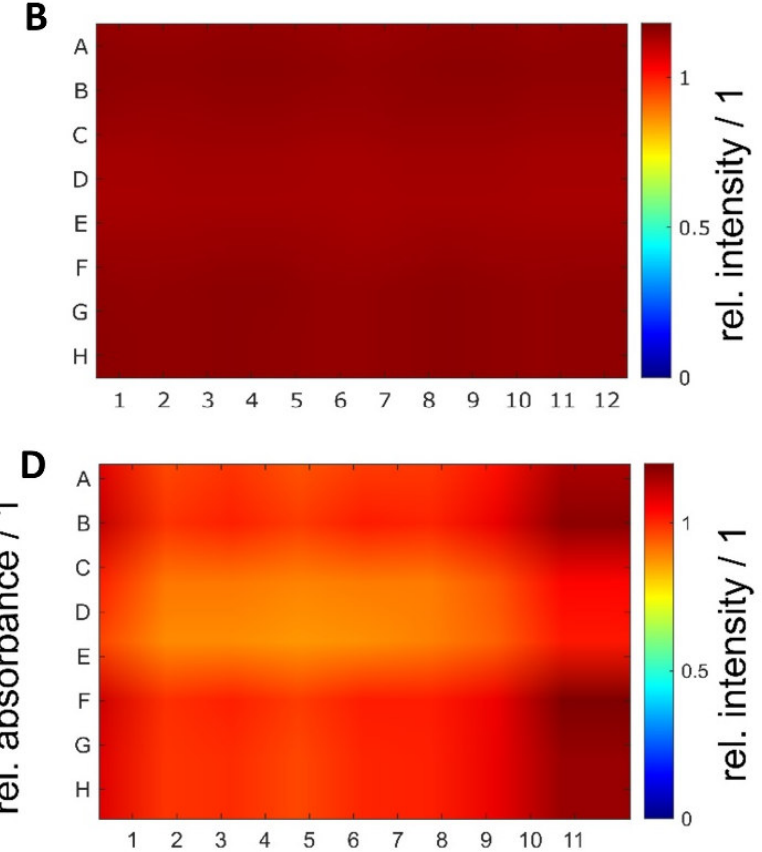

Figure 3: (Color online) Non-equidistant LED arrangement and results of homogeneity measurements. A nonlinear optimization of the individual LED positions in the $\boldsymbol{x} \boldsymbol{y}$-plane of the printed circuit board resulted in in a symmetric but not equidistant arrangement with decreasing distances on the outside. For a better understanding of the LED arrangement, the position of the irradiated plate is illustrated as well (Figure 2a). The irradiance distribution at the sample plane was determined by optical simulations (Figure $2 \mathrm{~b}$ ) and measured with a chemical actinometer (Figure 2c) and a radiometer (Figure 2d). In the optical simulations a very high uniformity with a theoretical coefficient of variation less than $0.1 \%$ $\left(c v_{\text {sim }}=0.08 \%\right)$ were calculated. Experimental evaluation of the uniformity resulted in variations of less than $10 \%$ (chemical actinometer $c v_{\text {act }}=9 \%$ and radiometer $c v_{\text {rad }}=8 \%$ ). 


\section{A new High-Throughput-Screening-assay for Photoantimicrobials}

To fully characterize the irradiation device, the spectral power distribution and irradiance were measured for every LED module (violet, blue, green, amber, and red). From these measurements, several spectral parameters, including the actual peak wavelength and the full width at half maximum, were calculated and the average irradiance was determined. Spectral power distributions varied between $15 \mathrm{~nm}$ FWHM for violet LEDs and $33 \mathrm{~nm}$ FWHM for green LEDs. Average irradiance was the highest for the violet LED module with $E_{m}=13 \pm 1.0 \mathrm{~mW} / \mathrm{cm}^{2}$ and the lowest for the amber LED module with $E_{m}=1.1 \pm 0.08 \mathrm{~mW} / \mathrm{cm}^{2}$. All results on the irradiation conditions are reported in Table 1.

Table 1: Optical characterization of the irradiation device. The spectral power distributions and the irradiance at the sample plane were measured for all LED module colors. From the spectral data, the actual peak wavelength, the full width at half of the intensity maximum (FWHM), and the full width at ten percent of the intensity maximum $\left(\mathrm{FW} 0.1 \cdot I_{\max }\right)$ were obtained by fitting a sum of Gaussian functions to the data. From the irradiance measurements, the arithmetic mean $\left(E_{m}\right)$, the standard deviation $(S D)$ and the coefficient of variation $(c v)$ were calculated.

\begin{tabular}{l|cccc|ccc}
\cline { 2 - 8 } $\begin{array}{l}\text { LED module } \\
\text { color }\end{array}$ & \multicolumn{4}{|c|}{ spectral information } & \multicolumn{3}{c}{ irradiance } \\
& $\begin{array}{c}\text { wavelength } \\
{[\mathrm{nm}]}\end{array}$ & $\begin{array}{c}\text { FWHM } \\
{[\mathrm{nm}]}\end{array}$ & $\begin{array}{c}\mathrm{FW} 0,1 \cdot I_{\text {max }} \\
{[\mathrm{nm}]}\end{array}$ & $\begin{array}{c}R^{2} \\
{[1]}\end{array}$ & $\begin{array}{c}E_{m} \\
{\left[\mathrm{~mW} / \mathrm{cm}^{2}\right]}\end{array}$ & $\begin{array}{c}S D \\
{\left[\mathrm{~mW} / \mathrm{cm}^{2}\right]}\end{array}$ & $\begin{array}{c}c v \\
{[1]}\end{array}$ \\
\hline violet & 428 & 15 & 36 & 0.9994 & 13 & 1.0 & 0.081 \\
blue & 478 & 27 & 63 & 0.9991 & 8.7 & 0.70 & 0.076 \\
green & 523 & 33 & 78 & 0.9998 & 6.0 & 0.44 & 0.073 \\
amber & 598 & 16 & 38 & 0.9994 & 1.1 & 0.084 & 0.078 \\
red & 640 & 18 & 45 & 0.9999 & 6.4 & 0.47 & 0.074 \\
\hline \hline
\end{tabular}

\subsection{Establishment of a HTS-Protocol}

A high-throughput assay was developed based on the gold-standard microdilution method (Benkova et al.; Wiegand et al., 2008). Like the classic method, the HTS started with an overnight culture of the selected test organisms (E. coli, S. aureus, and C. albicans) and, separately, with the test compounds or extracts of interest (Figure 2). In the next step, a stock solution of the test extracts or compounds was generated in DMSO and successively diluted in media. MHB was used for the bacteria, while the yeast was cultured in RPMI, double strength. In Figure 2, a flow chart is displayed, including the pipetting scheme for the testing extracts. In Figure S1, the respective flow chart with a pipetting plan for pure compounds is shown. In contrast to the classic microdilution assay, a blank of each tested compound was needed to avoid false-negative effects in the final OD reading which determines the MIC. The next step was a preincubation step, followed by an irradiation step with the chosen wavelength and light doses. A dark control was conducted in parallel to examine the effect of light. After the (mock)-light treatment step, the plates were incubated for $\mathrm{t}=24 \mathrm{~h}$. Finally, an OD measurement was performed to quantify the MIC, and -if needed- the treated dilutions were submitted to a CFU count to determine the MBC.

\subsection{Establishment of the Photoantimicrobial Assay and its Validation with known PSs}

In the first step, the light tolerance of the test organisms (i.e., E. coli, S. aureus, and C. albicans) was examined. To achieve this, the microorganisms were irradiated utilizing the five different LEDmodules with light doses up to $H=30 \mathrm{~J} / \mathrm{cm}^{2}$. Under all tested light conditions (Figure 4), the irradiated populations were not affected compared to the non-irradiated control groups. Therefore, all observed effects will be due to a combined effect of the light and the test compound/extract. 
A

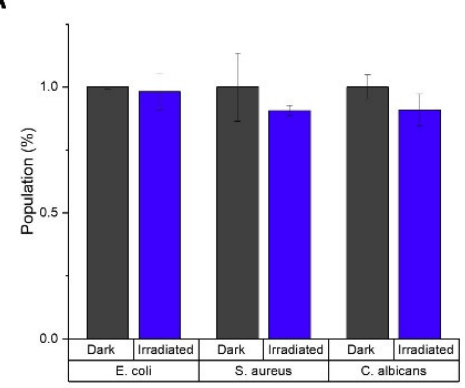

D

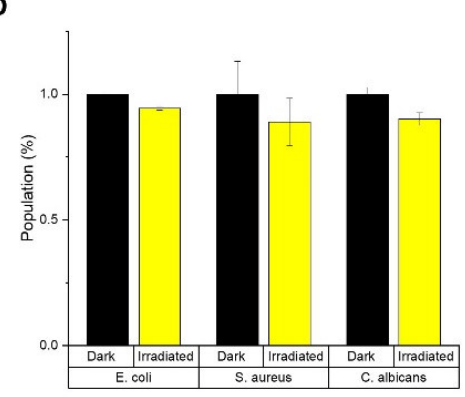

B

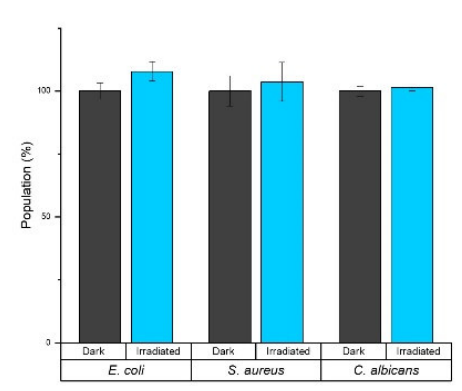

E

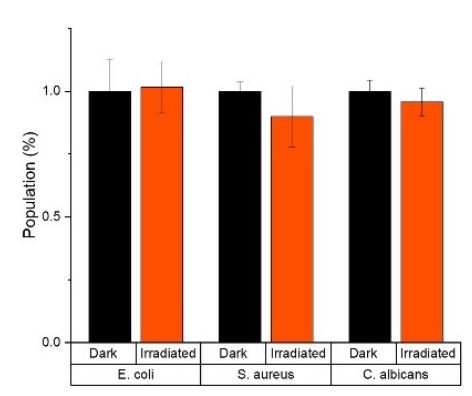

C

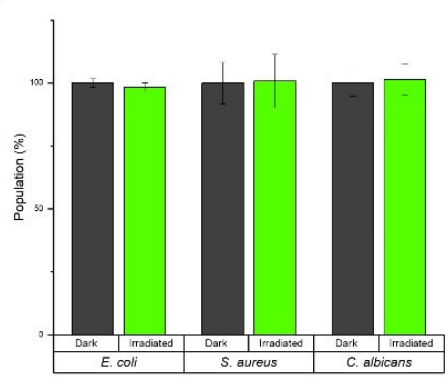

Figure 4: Effect of light irradiation on the growth of E. coli, S. aureus, and C. albicans. A) $\lambda_{\text {irr }}=428 \mathrm{~nm}, H=30 \mathrm{~J} / \mathrm{cm}^{2}$, B) $\lambda_{\text {irr }}=478 \mathrm{~nm}, H=30 \mathrm{~J} / \mathrm{cm}^{2}$, C) $\lambda_{\text {irr }}=523 \mathrm{~nm}, H=30 \mathrm{~J} / \mathrm{cm}^{2}$, D) $\lambda_{\text {irr }}=598 \mathrm{~nm}, \mathrm{H}=9.3 \mathrm{~J} / \mathrm{cm}^{2}$, and E) $\lambda_{\text {irr }}=640 \mathrm{~nm}, H=30$ $\mathrm{J} / \mathrm{cm}^{2}$.

310 Next, well-established photosensitizers were selected. In detail, phenalenone, curcumin, rose bengal 311 (RB), methylene blue (MB), and a Hypericum perforatum (HP) extract (photoactive ingredient: 312 hypericin) were chosen to validate the irradiation setup. These positive controls (PCs) were 313 characterized by absorption properties complementary to the LED-emission profiles (Figure 5). As depicted, several LED-modules can activate individual PCs, as their absorbance bands fit more than one LED-module. In Table 2, the PhotoMIC values - generated in accordance with the EUCAST guidelines - are given. For each LED-module and tested microorganism, the most active PS is represented in Figure 5, though for several LED-modules a selection of PSs worked. For example, the growth of $S$. aureus was not only impeded with yellow light $\left(\lambda_{\text {irr }}=523 \mathrm{~nm}, 30 \mathrm{~J} / \mathrm{cm}^{2}\right)$ and RB $(\mathrm{c}=6$ $\mu \mathrm{g} / \mathrm{mL}$, Table 2), but also with yellow light $\left(\lambda_{\text {irr }}=523 \mathrm{~nm}, 30 \mathrm{~J} / \mathrm{cm}^{2}\right)$ and $\mathrm{HP}(\mathrm{c}=150 \mu \mathrm{g} / \mathrm{mL})$. The MIC using RB ( $\mathrm{c}=6 \mu \mathrm{g} / \mathrm{mL}$ ), however, was more promising and is thus displayed in Table 2 . The doses-response curves are depicted in Figure S2-S6. 


\section{A new High-Throughput-Screening-assay for Photoantimicrobials}

Figure 5 Absorbance spectra of PCs versus emission spectra of the LED modules $\left(\lambda_{\text {irr }}=428,478,523,598\right.$, and $640 \mathrm{~nm}$

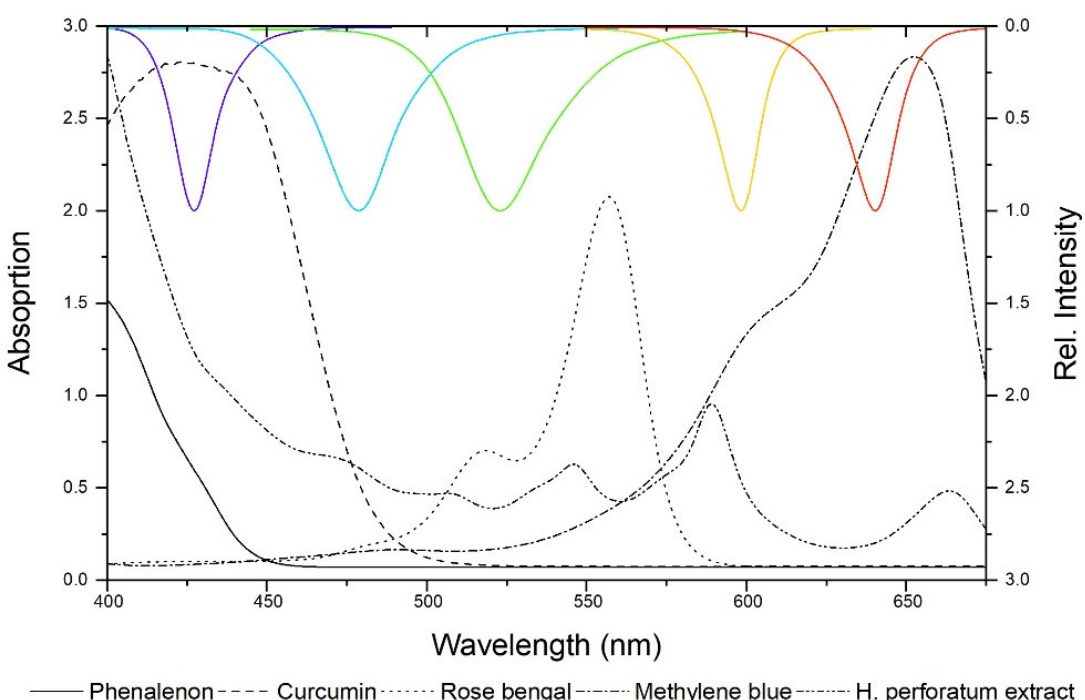

Table 2: Overview of the minimal inhibition concentrations under irradiation (PhotoMIC) of the investigated positive controls regarding the three tested MOs. In the table, for each PS are given the PhotoMIC value with the utilized preincubation time (PI) and light dose $(H)$. The last column contains MICs of standard AB without light-irradiation.

\begin{tabular}{|c|c|c|c|c|c|c|}
\hline & $428 \mathrm{~nm}$ & $478 \mathrm{~nm}$ & $523 \mathrm{~nm}$ & $598 \mathrm{~nm}$ & $640 \mathrm{~nm}$ & Dark \\
\hline $\begin{array}{l}\text { C. albicans } \\
\text { (yeast) }\end{array}$ & $\begin{array}{l}\text { Curc } \\
4 \mu \mathrm{g} / \mathrm{mL} \\
(10.9 \mu \mathrm{M}) \\
60 \mathrm{~min} \\
30 \mathrm{~J} / \mathrm{cm}^{2}\end{array}$ & $\begin{array}{l}\text { Curc } \\
30 \mu \mathrm{g} / \mathrm{mL} \\
(81.5 \mu \mathrm{M}) \\
10 \mathrm{~min} \\
9.3 \mathrm{~J} / \mathrm{cm}^{2}\end{array}$ & $\begin{array}{l}\mathrm{HP} \\
50 \mu \mathrm{g} / \mathrm{mL} \\
10 \mathrm{~min} \\
30 \mathrm{~J} / \mathrm{cm}^{2}\end{array}$ & $\begin{array}{l}\text { HP } \\
200 \mu \mathrm{g} / \mathrm{mL} \\
10 \mathrm{~min} \\
9.3 \mathrm{~J} / \mathrm{cm}^{2}\end{array}$ & $\begin{array}{l}\text { MB } \\
2.5 \mu \mathrm{g} / \mathrm{mL} \\
(7.8 \mu \mathrm{M}) \\
60 \mathrm{~min} \\
30 \mathrm{~J} / \mathrm{cm}^{2}\end{array}$ & $\begin{array}{l}\text { AMP } \\
0.2 \mu \mathrm{g} / \mathrm{mL} \\
(0.2 \mu \mathrm{M})\end{array}$ \\
\hline $\begin{array}{l}\text { E. coli } \\
\text { (gram } \\
\text { negative) }\end{array}$ & $\begin{array}{l}\text { Curc } \\
40 \mu \mathrm{g} / \mathrm{mL} \\
(108.6 \mu \mathrm{M}) \\
10 \mathrm{~min} \\
30 \mathrm{~J} / \mathrm{cm}^{2}\end{array}$ & $\begin{array}{l}\text { PN* } \\
75 \mu \mathrm{g} / \mathrm{mL} \\
(416.2 \mu \mathrm{M}) \\
10 \mathrm{~min} \\
9.3 \mathrm{~J} / \mathrm{cm}^{2}\end{array}$ & $\begin{array}{l}\mathrm{RB}^{*} \\
150 \mu \mathrm{g} / \mathrm{mL} \\
(154.1 \mu \mathrm{M}) \\
10 \mathrm{~min} \\
30 \mathrm{~J} / \mathrm{cm}^{2}\end{array}$ & n.s. & n.s. & $\begin{array}{l}\text { CAP } \\
2 \mu \mathrm{g} / \mathrm{mL} \\
(6.2 \mu \mathrm{M})\end{array}$ \\
\hline $\begin{array}{l}\text { S. aureus } \\
\text { (gram } \\
\text { positive) }\end{array}$ & $\begin{array}{l}\text { Curc } \\
4 \mu \mathrm{g} / \mathrm{mL} \\
(10.9 \mu \mathrm{M}) \\
10 \mathrm{~min} \\
9.3 \mathrm{~J} / \mathrm{cm}^{2}\end{array}$ & $\begin{array}{l}\text { PN } \\
25 \mu \mathrm{g} / \mathrm{mL} \\
(138.7 \mu \mathrm{M}) \\
10 \mathrm{~min} \\
9.3 \mathrm{~J} / \mathrm{cm}^{2}\end{array}$ & $\begin{array}{l}\text { RB* } \\
4 \mu \mathrm{g} / \mathrm{mL} \\
(4.1 \mu \mathrm{M}) \\
10 \mathrm{~min} \\
30 \mathrm{~J} / \mathrm{cm}^{2}\end{array}$ & $\begin{array}{l}\mathrm{HP} \\
150 \mu \mathrm{g} / \mathrm{mL} \\
10 \mathrm{~min} \\
9.3 \mathrm{~J} / \mathrm{cm}^{2}\end{array}$ & n.d. & $\begin{array}{l}\text { ERY } \\
1 \mu \mathrm{g} / \mathrm{mL} \\
(1.3 \mu \mathrm{M})\end{array}$ \\
\hline
\end{tabular}

Curc $=$ Curcumin, $\mathrm{PN}=$ Phenalenone, $\mathrm{RB}=$ Rose bengal, HP = Hypericum perforatum extract; $*$ other PS worked as well. N.d. $=$ Not detected.; $. \mathrm{s} .=$ not selective; $\mathrm{CAP}=$ Chloramphicol; $\mathrm{AMP}=$ Amphothericin B; ERY $=$ Erythromycin. For a full discussion see SI Chapter 1.

\subsection{Mycochemical Analysis of Selected Cortinarius species}

Based on their colorful appearance, the fruiting bodies of six different Cortinarius species (i.e., were selected to evaluate our photo-antimicrobial assay (See Table S1 for collection information). In a first step, the dried material was extracted and the obtained extracts (see Table 3) were analyzed spectroscopically (UV-Vis, Figure S7) as well as chromatographically (i.e., HPLC combined with several hyphenated detectors (i.e., DAD, FLD, ELSD, MS see Figure S8-S10)). The results showed 


\section{A new High-Throughput-Screening-assay for Photoantimicrobials}

that the extract of C.xanthophyllus is not only the most complex but also the most intensely colored one (Figure S7 and S11). In detail, five intense peaks were detected at $\lambda=254 \mathrm{~nm}$ (Table S3). The

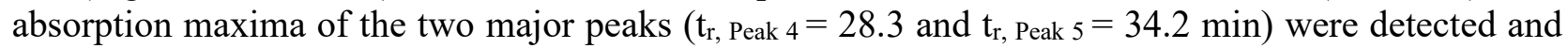
equaled $\lambda_{\max }$, Peak $4=436 \mathrm{~nm}$ and $\lambda_{\max }$, Peak $5=525 \mathrm{~nm}$ (See Figure $\mathrm{S} 12 \mathrm{UV}-\mathrm{Vis}$ spectra).

The mass spectrometric analysis revealed a mass of $\mathrm{m} / \mathrm{z}=283[\mathrm{M}-\mathrm{H}]^{-}$for Peak 4 and the chemical formula $\mathrm{C}_{16} \mathrm{H}_{12} \mathrm{O}_{5}$. Taking the characteristic fluorescence properties of Peak 4 (Figure $\mathrm{S} 8 \mathrm{~A}$ ) and the TLC work of Hofbauer (Hofbauer, 1983) into account, this peak was annotated as parietin and confirmed by comparison with an authentic sample (Figure S13). Also, Peak 2, 3, and 5 were characterized by anthraquinone-like absorption spectra (Figure S12). The red shift of the absorption maxima $(\Delta \lambda=57-87 \mathrm{~nm}$, as compared to Peak 4 (parietin)) indicated an extended chromophore and thus hinted towards dimeric AQ-like structures. While Peak $2\left(t_{\mathrm{r}}=25.4 \mathrm{~min}\right)$ and Peak $3\left(\mathrm{t}_{\mathrm{r}}=26.9 \mathrm{~min}\right)$ were also detected in the extract of C. rufo-olivaceus, they were putatively assigned as rufoolivacin A \& C (Gill and Steglich, 1987; Zhang et al., 2009; Gao et al., 2010), which was in accordance with their mass peak of $\mathrm{m} / \mathrm{z}=557.2[\mathrm{M}+\mathrm{H}]^{+}$(Table S3). Peak $5\left(\mathrm{~m} / \mathrm{z}=556.2[\mathrm{M}+\mathrm{H}]^{+}\right)$was not assigned yet, but might be an oxidated derivative of phlegmacin $(\mathrm{MW}=576.6 \mathrm{~g} / \mathrm{mol})$, which was described in C. xanthophyllus (Hofbauer, 1983). Plenty of dimeric anthraquinones are known from related Cortinariaceae (Gill and Steglich, 1987; Elsworth et al., 1999; Zhang et al., 2009; Gao et al., 2010) and thus seems to be a reasonable putative annotation. Further discussion of the metabolic profiles can be found in the supplementary part (Chapter 2.2.3).

Table 3: Initial weight of biomaterial of Cortinarius species and yield of extracts.

\begin{tabular}{|c|c|c|c|}
\hline & $\begin{array}{c}\text { Biomaterial } \\
{[\mathrm{mg}]}\end{array}$ & $\begin{array}{c}\text { Yield of extract } \\
{[\mathrm{mg},(\%)]}\end{array}$ & $\begin{array}{c}\text { Visual appearance } \\
\text { extract }\end{array}$ \\
\hline C. rufo-olivaceus & 1784.9 & $91.0(5.1)$ & Dark red, dull \\
\hline C. venetus & 1944.0 & $26.7(1.4)$ & Light yellow, greasy, \\
\hline C. tophaceus & 1643.7 & $14.6(0.9)$ & Light yellow, muddy \\
\hline C. traganus & 1709.7 & $18.2(1.1)$ & Dark yellow, muddy \\
\hline C. trivialis & 1958.1 & $22.0(1.1)$ & Dark yellow, greasy \\
\hline C. xanthophyllus & 1051.8 & $26.6(2.5)$ & Purple, earthy, powder \\
\hline
\end{tabular}

\subsection{Singlet-Oxygen Detection assay (DMA-Assay)}

The obtained extracts were submitted to the recently developed singlet oxygen high-throughput assay (DMA-assay, (Siewert et al., 2019)). Out of the six investigated extracts, two, namely C. xanthophyllus and C. rufo-olivaceus, showed the ability to produce ${ }^{1} \mathrm{O}_{2}$ after being irradiated with blue light (Table 4). C. xanthophyllus was the most active extract: Irradiated at $\lambda=468 \pm 27 \mathrm{~nm}\left(24.8 \mathrm{~J} / \mathrm{cm}^{2}\right)$, the extract produced $187 \%$ singlet oxygen as compared to the well-known photosensitizer phenalen-1-one (Schmidt et al., 1994; Espinoza et al., 2016). Hence, this extract originating from natural sources showed promising photosensitizing activity as promising as those of synthetic compounds, such as phenalene-1-one. 


\section{A new High-Throughput-Screening-assay for Photoantimicrobials}

Table 4: Results of the DMA-assay (blue light irradiation relative to phenalene-1-one).

\begin{tabular}{|c|c|c|}
\hline & Singlet Oxygen Production [\%] & Standard deviation [\%] \\
\hline C. rufo-olivaceus & 49.6 & 2.55 \\
\hline C. tophaceus & 3.1 & 1.7 \\
\hline C. traganus & 0.2 & 1.1 \\
\hline C. trivialis & 4.2 & 2.0 \\
\hline C. venetus & 4.4 & 0.2 \\
\hline C. xanthophyllus & 187.1 & 2.1 \\
\hline
\end{tabular}

\subsection{Cortinarius xanthophyllus contains photoantimicrobials active against Staphylococcus aureus and Candida albicans}

Submitting all six extracts to the (photo)antimicrobial assay revealed that all extracts are inactive (c $>$ $50 \mu \mathrm{g} / \mathrm{mL}$ ) under the exclusion of light (Figure 6-8). Under light-irradiation, however, the activity of the purple extract of $C$. xanthophyllus was significantly enhanced: The growth of the gram-positive bacterium $S$. aureus (Figure 8) was completely inhibited with an extract concentration as low as c $=$ $7.5 \mu \mathrm{g} / \mathrm{mL}$ and a light dose of $\mathrm{H}=30 \mathrm{~J} / \mathrm{cm}^{2}(\lambda=478 \mathrm{~nm})$. This also holds true for the photoactivity against the yeast $C$. albicans, where an extract concentration of $\mathrm{c}=75 \mu \mathrm{g} / \mathrm{mL}\left(\mathrm{H}=30 \mathrm{~J} / \mathrm{cm}^{2}\right)$ led to complete growth inhibition (Figure 6). Against the gram-negative E. coli, however, C. xanthophyllus was inactive in the dark and under irradiation (Figure 7).

A weak enhancement of the growth inhibition effect was also seen for the C. rufo-olivaceus extract against $S$. aureus $\left(\mathrm{IC}_{50} \sim 50 \mu \mathrm{g} / \mathrm{mL}\right)$. Nevertheless, this extract did not affect $C$. albicans under the tested conditions.
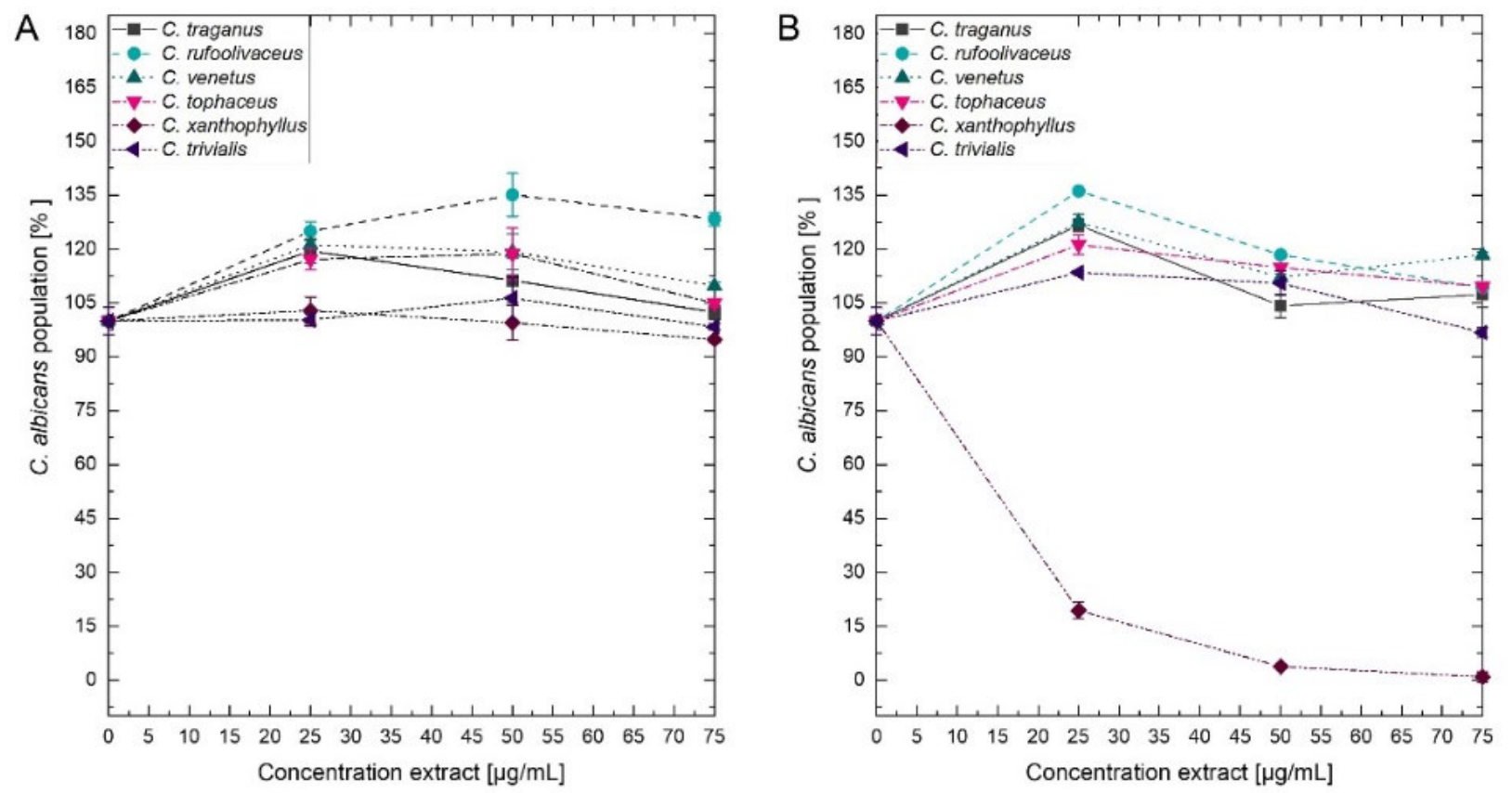

Figure 6: Dose-response curves of C. albicans treated with Cortinarius extracts. On the left side (A) dark controls are shown. The right graph (B) represents the irradiated experiments $\left(\lambda=470 \mathrm{~nm}, \mathrm{H}=30 \mathrm{~J} / \mathrm{cm}^{2}, \mathrm{PI}=60 \mathrm{~min}\right)$. 

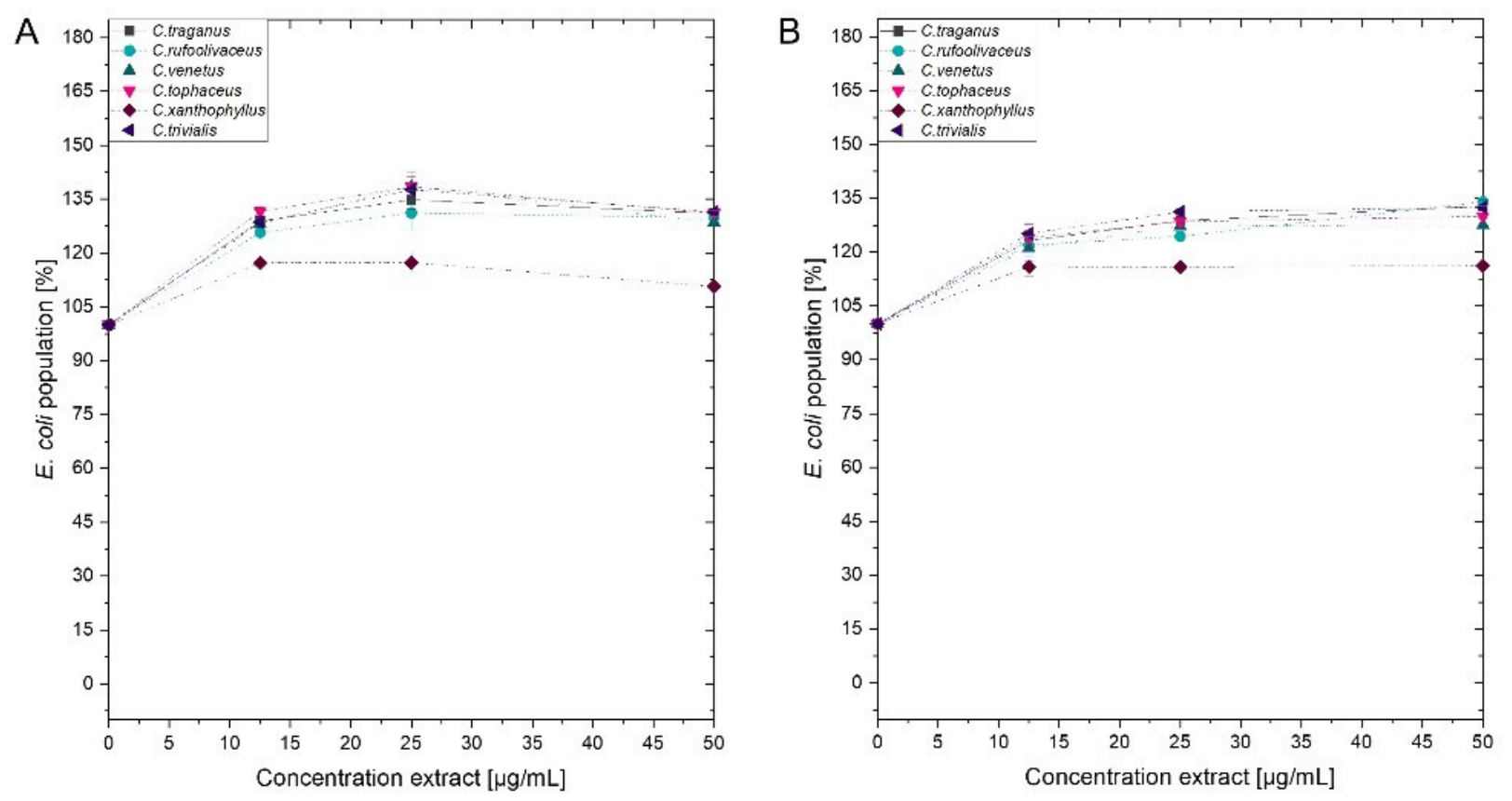

Figure 7: Dose-response curves of E. coli treated with Cortinarius extracts. On the left side (A) dark controls are shown. The right graph (B) represents the irradiated experiments $\left(\lambda=470 \mathrm{~nm}, 30 \mathrm{~J} / \mathrm{cm}^{2}, \mathrm{PI}=60 \mathrm{~min}\right)$.
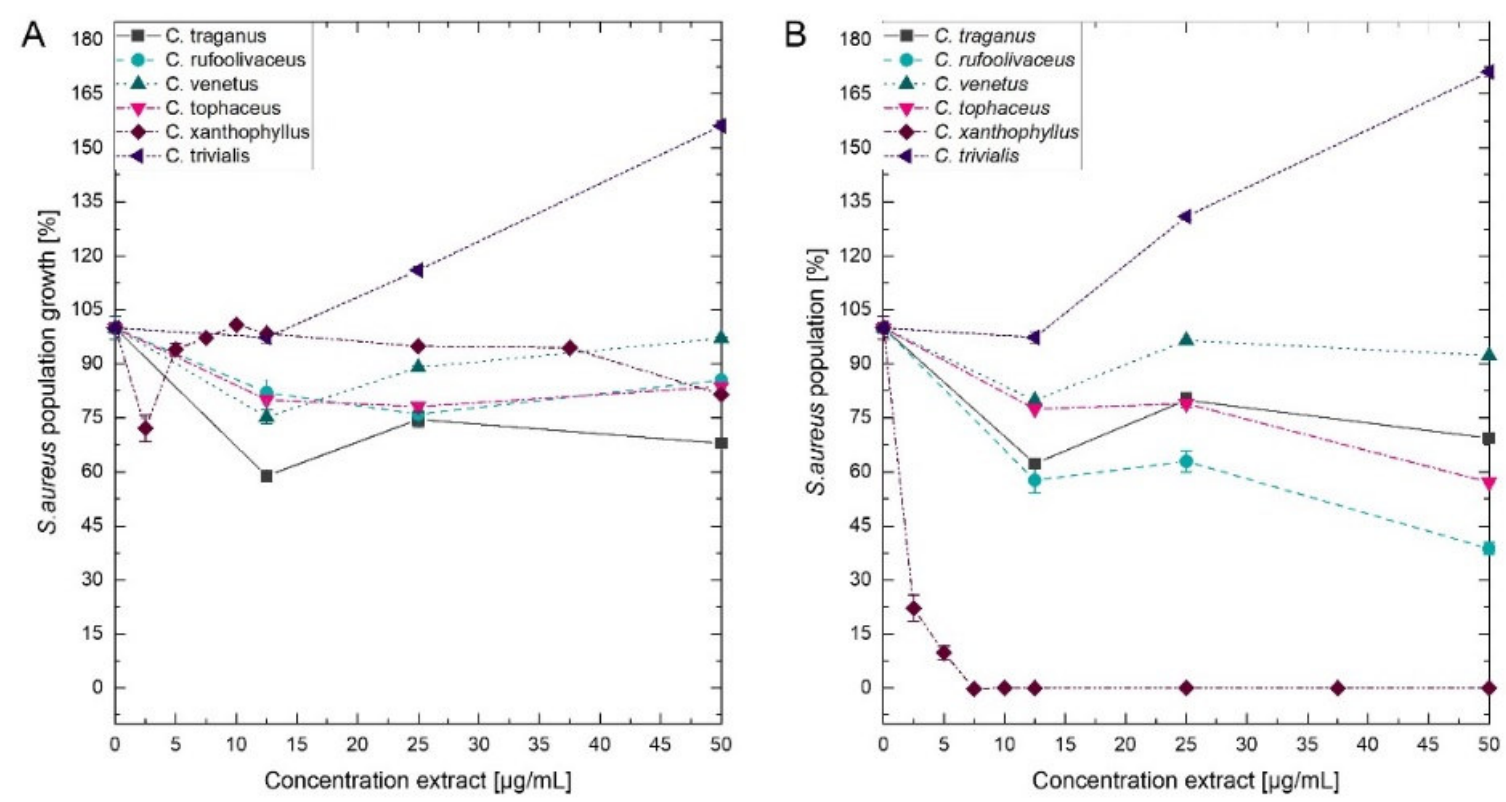

392 Figure 8: Dose-response curves of $S$. aureus treated with Cortinarius extracts. A) Growth inhibition under dark conditions. 


\section{Discussion}

397 The hypothesis we wanted to test in course of this study was that light is a neglected co-factor in antimicrobial screening assays. Therefore, a convenient HTS-screening assay based on the EUCAST protocol was established and validated. In a first step, an innovative LED-panel was required achieving a homogenous irradiation of a 96-well plate. Finally, the hypothesis was be tested with a set of six 401 different Cortinarius species.

\subsection{The SciLED irradiation system and its improved uniform irradiance distribution}

403

404

405

406

407

408

409

410

To achieve the first objective - the homogenous irradiation of a 96-well plate - the distance and number of the LEDs was optimized by simulations until the coefficient of variation $c v$ was estimated to be less than one percent. Irradiance measurements and chemical actinometer measurements (Figure 3) confirmed the homogeneous irradiance. Nevertheless, the actual coefficient of variation from irradiance measurements was in the range between seven to nine percent. Deviations between the simulation and the measurement can be attributed to differences between the modeled and the actual radiant intensity distribution of the LED, variations in the radiometric power of individual LEDs, and measurement uncertainties.

Although the real uniformity $(c v=8 \%)$ of the irradiation system with non-equidistant LED arrangement presented in this work was less than the expected uniformity from the simulations $\left(c v_{\operatorname{sim}}=0.08 \%\right)$, the achieved homogeneity over the whole sample area was still significantly better compared to equidistant LED positioning. An optical simulation of a $6 \times 4$ LED array with an equidistant arrangement $(\Delta x=35 \mathrm{~mm}, \Delta y=35 \mathrm{~mm})$ resulted in a less homogeneous irradiance distribution $\left(c v_{\text {sim }}=5 \%\right)$ compared to the existing non-equidistant arrangement $\left(c v_{\text {sim }}=0.08 \%\right)$. To understand the positive effects of a non-equidistant positioning, the non-uniform radiant intensity distribution of LEDs must be taken into account. Considering just one LED, the resulting irradiance distribution on the irradiated plane is decreasing nonlinear with an increased distance from the center. Placing two LEDs with a certain distance $d$ next to each other, parts of the irradiance will overlap. Due to the superposition principle, the resulting irradiance distribution is the sum of every single one (Figure 9). Depending on the distance, the irradiance in the intermediate area between the two LEDs is enhanced, reduced, or constant. This dependence of the irradiance distribution from the LED distance is shown in Figure 9 for three different distances $d$. Using an array of $n \times m$ LEDs with $n>2$ and $m \geq 1$, the overlapping effect is amplified. To achieve a uniform distribution, the right LED arrangement is crucial. The LED distances for a uniform irradiance depends on the number of LEDs, the viewing angle $\theta_{1 / 2}$ and the working distance $z$. As a rule of thumb, for LEDs with a wide viewing angle, the distances of the inner LEDs should be wider than the distance of the outer ones. 


\section{A new High-Throughput-Screening-assay for Photoantimicrobials}
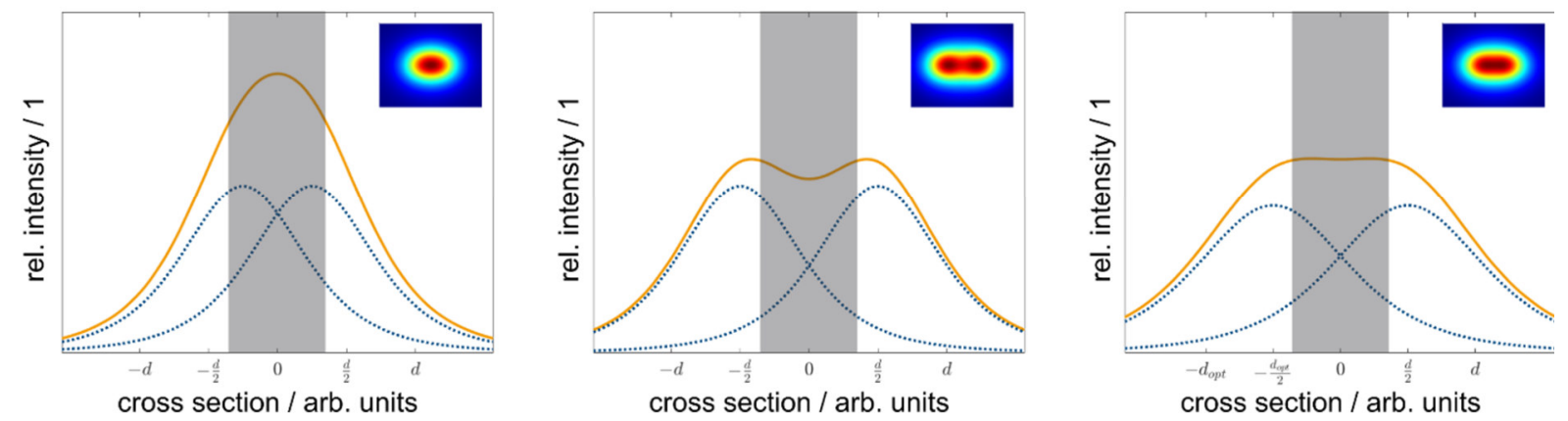

Figure 9. Side-view of the irradiance distribution depending on LED distance. Depending on the LED distance $\boldsymbol{d}$, the resulting irradiance from the two overlapping LED irradiance distributions at the sample plane differs. Individual LED irradiance distributions are represented as dotted lines (blue), and the resulting distributions are shown as solid lines (orange) The grey bar indicates the max. width of the sample plate. If the LED distance $\boldsymbol{d}$ is too low, the overlap in the center is high, and the resulting irradiance is enhanced (A). For a too large LED distance $\boldsymbol{d}$, the overlap is small, and the resulting irradiance is reduced (B). Using the optimal LED distance $\boldsymbol{d}_{\text {opt }}$, each LED contributes the right amount, and the resulting irradiance in the center is constant $(\mathrm{C})$.

However, a uniform irradiance comes with a price. Due to the positioning scheme, the average irradiance decreased by ten percent compared to the equidistant arrangement. Simulations of different equidistant LED positions have shown that the resulting average irradiance increased by reducing the spacing between the individual LED, yet the uniformity decreased. Depending on the purpose of the irradiation system, a tradeoff between irradiance and homogeneity is necessary. For this work, a uniform distribution was essential to accomplish comparable irradiation conditions within the 96-well plate.

Optical characterization measurements shown in Table 1 indicate that the actual peak wavelengths are within the specifications from the datasheets for all but the red LEDs. With a nominal wavelength range from $\lambda=624 \mathrm{~nm}$ to $\lambda=634 \mathrm{~nm}$ given by the manufacturer and an actual peak wavelength of $\lambda$ $=640 \mathrm{~nm}$ a divergence was observed. This deviation may result from a different characterization method in the datasheet. The LED manufacturer refers to a dominant wavelength, which takes the relative spectral sensitivity of human visual perception of brightness (luminosity function) into account (Lumileds Holding B.V. 2019). The peak wavelength in this work refers to an absolute spectral measurement without considering the luminosity function of the human eye. Irradiation measurements at the sample distance revealed a variation in the achieved intensities from a maximum irradiance of $E_{m}=13 \pm 1.0 \mathrm{~mW} / \mathrm{cm}^{2}$ for violet LEDs and a minimum irradiance of $E_{m}=1.1 \pm 0.08 \mathrm{~mW} / \mathrm{cm}^{2}$ for amber LEDs. These fluctuations can be explained by different designs and composition of each singlecolor LED. To achieve different emission wavelengths, different semiconductor combinations with different dopings are used in addition to various packaging layouts (Schubert, 2006). These intrinsic variations result in different irradiances.

\subsection{Establishment and Validation of a Screening Photoantimicrobial Assay}

The EUCAST microdilution assay - being launched to allow a better inter-laboratory reproducibility inspired the established photoantimicrobial HTS. While antimicrobial assays heavily depend on the testing conditions, one aim of EUCAST is to boost the development of new antimicrobials by the enablement of inter-laboratory comparisons. Specifically, photoantimicrobials are part of a promising treatment alternative, the so-called Photoantimicrobial chemotherapy (PACT) or antimicrobial photodynamic inhibition (aPDI) (Wainwright, 2009). While the therapy depends on a completely 


\section{A new High-Throughput-Screening-assay for Photoantimicrobials}

different mechanism (i.e., ROS production due to the interplay of light and a photosensitizer) compared to well-established antibiotics, it is active against multi-resistant pathogens and the risk of resistancedevelopment is relatively low (Maisch, 2015). Nevertheless, despite these attractive aspects, wide acceptance of PACT is lacking. One limitation next to others (Wainwright, 2009) is the limited throughput of established assays: Often, one PS-candidate and one concentration are irradiated by the time, leading to exorbitantly time consuming experiments. On the other hand, testing multiple parameters (concentrations, microorganism, or drug-candidates) on one plate lacked comparability due to an uneven light distribution (Ogonowska et al., 2019). Thus, the limited throughput impeded the study of extensive libraries of PS-candidate and hence the classical lead-to-hit approach of medicinal chemistry.

The EUCAST protocol tests an antibiotic (AB) usually with ten concentrations and defines the MIC by the value which is the lowest concentration inhibiting the growth completely as determined by the lack of turbidity. To test photoantimicrobials, a blank measurement of each concentration is necessary. The test solutions are colored, and the blank subtraction is necessary to avoid false-negative read-outs during the OD measurement. Furthermore, a triplicate of each concentration is needed account for the biological variability. This led us to the, in Figure S8 displayed, pipetting scheme, which allows testing the effect of two PSs against one microorganism. While for classic EUCAST susceptibility assays only these variables (i.e., tested microorganism and concentration range of the AB) are crucial, the number of variables exceeds in the photoantimicrobial assay: In addition to the preincubation time, irradiation time, and light doses, as well as light power and the irradiation wavelength itself are of interest.

The established scheme (Figure 2) and the workability were tested with the known PSs curcumin, rose bengal (RB), methylene blue (MB), phenalenone (PN), and a Hypericum extract (HP). The irradiation wavelength changed according to the absorbance pattern of the PS (Figure 5). The light dose was set to $H=30 \mathrm{~J} / \mathrm{cm}^{2}$, which equated to the utilized dose from several published studies (Cieplik et al., 2016; de Annunzio et al., 2018; Merigo et al., 2019) and furthermore was shown to be non-toxic against the tested microorganisms alone (Figure 4). While this is per se not as important as for photocytotoxicity (Wainwright, 2009) studies, we choose this dose to truly see the light-effect of the PSs. PhotoMIC values were generated for this variety of PSs against the pathogenic microorganisms S. aureus, $C$. albicans, and $E$. coli utilizing the LED modules with an irradiation wavelength of $\lambda_{\text {irr }}=428,478$, 523,598 , and $640 \mathrm{~nm}$. To the best knowledge of the authors, Table 2 represents the first comprehensive overview of the PhotoMIC values of common PSs. Although literature values cannot be easily compared due to the discussed, yet not standardized parameters (Haukvik et al., 2009), our obtained values fit the reported ones (See Supplementary Part, Chapter 1.2 for the full discussion). An international agreement on standard values for the additional irradiation parameters would be helpful in the process of hit-lead optimization.

The gram-negative bacteria $E$. coli was resistant against the tested lipophilic and neutral PSs especially during the irradiation with yellow and red light (Table 2). This is well-known (see discussion SI chapter 4.1) and reasoned by their negatively charged membrane (Minnock et al., 2000; Bresolí-Obach et al., 2018; Galstyan et al., 2018).

To allow a screening of biological sources such as plant extracts or fungal extracts in the frame of bioactivity guided isolation, the pipetting scheme displayed in Figure 2 was established. Due to the even light distribution, up to seven extracts à three concentrations can be screened against one pathogenic microorganism in biological triplicates. By a slight modification of the testing logic on the other hand, a fast determination of PhotoMIC against a broader variety of microorganisms in analogy to the EUCAST scheme is possible (i.e., up to seven microorganisms against one PSs, no triplicates). 


\section{A new High-Throughput-Screening-assay for Photoantimicrobials}

\subsection{Utilization of the Screening Assay Yielded a Promising Hit}

As a sample set, extracts of six different Cortinarius species (Table 3 and Table S1) were investigated. The results of the antimicrobial assay (dark conditions) were in line with the results of Tiralongo and colleagues (Beattie et al., 2010). They investigated 117 different Australian Cortinarius species and could show that two-third of the species held an $\mathrm{IC}_{50}$ between $\mathrm{c}=20 \mu \mathrm{g} / \mathrm{mL}$ and $\mathrm{c}=200 \mu \mathrm{g} / \mathrm{mL}$ against the gram-positive bacterium S. aureus. In the present study, we determined MICs (instead of $\mathrm{IC}_{50}$ ), and were, under light exclusion, not able to see full inhibition of microbial growth with extract concentrations up to $\mathrm{c}=75 \mu \mathrm{g} / \mathrm{mL}$.

As shown in Figure 6, the addition of blue light exhilarated the antimicrobial activity of the intensely colored Cortinarius extract by more than tenfold: The extract of C. xanthophyllus was characterized by a PhotoMic of $\mathrm{c}=7.5 \mu \mathrm{g} / \mathrm{mL}$ and thus was even more effective than the established PS phenalenone $(\mathrm{MIC}=25 \mu \mathrm{g} / \mathrm{mL})$. In addition, the extract showed promising activity against $C$. albicans (Figure 6). Interestingly, this activity seems to be uptake depended, as a preincubation time of only ten minutes (instead of PI $=60 \mathrm{~min}$ ) showed no effect (Figure S14). Mycochemical analysis of the extract implicated three potential photoactive compounds (Figure S11). These pigments were tentatively annotated as rufoolivacin, parietin, and as an anhydro-phlegmacin-like compound (Table S3). Analysis of the HPLC-DAD chromatogram recorded at $\lambda=478 \mathrm{~nm}$ indicated that Peak 4 and Peak 5 absorb most of the incoming light, and thus might be responsible for the observed photoantimicrobial action. Parietin, usually isolated from the lichen Xanthoria parietina is known for its photoactive properties against cancer cells (Mugas et al., 2021) and against S. aureus (Comini et al., 2017). The chemical structure of Peak 5 is not assured yet and hampered by the limited availability of fungal material due to the rare occurrence of $C$. xanthophyllus. This Mediterranean species is listed on the red-list and thus endangered (Tingstad et al., 2017). Nevertheless, applying modern phytochemical techniques (e.g., LC-SPE-NMR, FBMN-assisted isolation) might help to reveal its chemical space and is part of future work.

\section{Conclusion}

The development of an uniform emitting LED-panel was presented, allowing a homogeneous irradiation of a complete 96-well plate. As consequence, a convenient HTS-assay to determine photoactivated minimal inhibitory concentrations (PhotoMIC) of pure compounds and extracts was established based on the EUCAST guideline. The light tolerance of the utilized model organisms (i.e., C. albicans, E. coli, and $S$. aureus) was tested and revealed that all microorganisms can cope with a light dose of $H=9.3 \mathrm{~J} / \mathrm{cm}^{2}$ or even $H=30 \mathrm{~J} / \mathrm{cm}^{2}$ of every tested wavelength (i.e., up to $9.3 \mathrm{~J} / \mathrm{cm}^{2}$ for $\lambda$ $=598$, up to $30 \mathrm{~J} / \mathrm{cm}^{2}$ for $\lambda=428,478,528,640 \mathrm{~nm}$ ). Standard photosensitizers were used to validate the assay and yielded the first comprehensive table accumulating a broad array of PhotoMic values under different irradiation conditions and against different pathogenic MOs. Lastly, submitting a test sample set of fungal extracts generated from the colored fruiting bodies of Cortinarius rufo-olivaceus, C. tophaceus, C.traganus, C. trivialis, C. venetus, and C. xanthophyllus showed that light is indeed one co-factor amplifying a moderate antimicrobial action of natural products. The most intensely colored extract, i.e., the one of $C$. xanthophyllus, showed the most promising activity of PhotoMIC $=7.5 \mu \mathrm{g} / \mathrm{mL}$ against $S$. aureus. The extract was also photoactive against $C$. albicans. Mycochemical analysis identified two peaks putatively responsible for the effect. One of them being the well-known natural PS parietin from the lichen Xanthoria parientina and the other one being a photochemically unexplored dimeric AQ. 


\section{A new High-Throughput-Screening-assay for Photoantimicrobials}

\section{Conflict of Interest}

The authors declare that the research was conducted in the absence of any commercial or financial relationships that could be construed as a potential conflict of interest.

\section{Author Contributions}

J.F. performed the antimicrobial assays and majority of the mycochemical analysis. F.H. performed the DMA-assay. H.S. and R.S. designed the irradiation device. H.S. performed the instrumental characterization. D.D. and D.J.A. performed pre-test of the AntiMic assay. P.V. contributed to the conception of the AntiMic assay. U.P. provided the biomaterial and phylogenetic input. B.S. designed the research, analyzed the mycochemical part, and wrote the manuscript with contributions of H.S. and J.F. All authors contributed to the final version of the manuscript.

\section{$8 \quad$ Funding}

The Austrian Science Fund (FWF P31950, BS and FWF T862, PV), the Tyrolean Science Fund, and the University of Innsbruck are thanked for their support.

\section{Acknowledgments}

H. Stuppner is kindly acknowledged for his support and input. Sarah Flatscher is acknowledged for her skillful help characterizing the LEDs.

\section{Supplementary Material}

See attached document.

\section{References}

B.V., L.H. (2019). DS198 LUXEON CZ Color Line Product Datasheet [Online]. Available: ttps://www.lumileds.com/products/color-leds/luxeon-cz-color-line/ [Accessed 01.02.2021 2021].

Bajgar, R., Pola, M., Hosik, J., Turjanica, P., Cengery, J., and Kolarova, H. (2020). New planar light source for the induction and monitoring of photodynamic processes in vitro. Journal of Biological Physics 46(1), 121-131. doi: 10.1007/s10867-020-09544-7.

Balouiri, M., Sadiki, M., and Ibnsouda, S.K. (2016). Methods for in vitro evaluating antimicrobial activity: A review. Journal of Pharmaceutical Analysis 6(2), 71-79. doi: https://doi.org/10.1016/j.jpha.2015.11.005.

Basnet, B.B., Liu, L., Bao, L., and Liu, H. (2017). Current and future perspective on antimicrobial and anti-parasitic activities of Ganoderma sp.: an update. Mycology 8(2), 111-124. doi: 10.1080/21501203.2017.1324529.

Beattie, K.D., Rouf, R., Gander, L., May, T.W., Ratkowsky, D., Donner, C.D., et al. (2010). Antibacterial metabolites from Australian macrofungi from the genus Cortinarius. Phytochemistry 71(8-9), 948-955. doi: 10.1016/j.phytochem.2010.03.016.

Benkova, M., Soukup, O., and Marek, J. Antimicrobial susceptibility testing: currently used methods and devices and the near future in clinical practice. Journal of Applied Microbiology n/a(n/a). doi: $10.1111 /$ jam.14704. 


\section{A new High-Throughput-Screening-assay for Photoantimicrobials}

Berenbaum, M. (1995). Phototoxicity of plant secondary metabolites: Insect and mammalian perspectives. Archives of Insect Biochemistry and Physiology 29(2), 119-134. doi: 10.1002/arch.940290204.

Betts, J.T. (1976). Solving the nonlinear least square problem: Application of a general method. Journal of Optimization Theory and Applications 18(4), 469-483. doi: 10.1007/BF00932656.

Bresolí-Obach, R., Gispert, I., Peña, D.G., Boga, S., Gulias, Ó., Agut, M., et al. (2018). Triphenylphosphonium cation: A valuable functional group for antimicrobial photodynamic therapy. Journal of Biophotonics 11(10), e201800054. doi: https://doi.org/10.1002/jbio.201800054.

Butler, M.C., Itotia, P.N., and Sullivan, J.M. (2010). A High-Throughput Biophotonics Instrument to Screen for Novel Ocular Photosensitizing Therapeutic Agents. Investigative Ophthalmology \& Visual Science 51(5), 2705-2720. doi: 10.1167/iovs.08-2862.

Calin, M.A., and Parasca, S.V. (2009). Light sources for photodynamic inactivation of bacteria. Lasers Med Sci 24(3), 453-460. doi: 10.1007/s10103-008-0588-5.

Chen, D., Zheng, H., Huang, Z., Lin, H., Ke, Z., Xie, S., et al. (2012). Light-Emitting Diode-Based Illumination System for $<\mathrm{i}>$ In Vitro $</ \mathrm{i}>$ Photodynamic Therapy. International Journal of Photoenergy 2012, 920671. doi: 10.1155/2012/920671.

Cieplik, F., Pummer, A., Leibl, C., Regensburger, J., Schmalz, G., Buchalla, W., et al. (2016). Photodynamic Inactivation of Root Canal Bacteria by Light Activation through Human Dental Hard and Simulated Surrounding Tissue. Front Microbiol 7, 929. doi: 10.3389/fmicb.2016.00929.

Coleman, T.F., and Li, Y. (1994). On the convergence of interior-reflective Newton methods for nonlinear minimization subject to bounds. Mathematical Programming 67(1), 189-224. doi: 10.1007/BF01582221.

Coleman, T.F., and Li, Y. (1996). An Interior Trust Region Approach for Nonlinear Minimization Subject to Bounds. SIAM Journal on Optimization 6(2), 418-445. doi: 10.1137/0806023.

Comini, L.R., Moran Vieyra, F.E., Mignone, R.A., Paez, P.L., Laura Mugas, M., Konigheim, B.S., et al. (2017). Parietin: an efficient photo-screening pigment in vivo with good photosensitizing and photodynamic antibacterial effects in vitro. Photochemical \& Photobiological Sciences 16(2), 201-210. doi: 10.1039/C6PP00334F.

de Annunzio, S.R., de Freitas, L.M., Blanco, A.L., da Costa, M.M., Carmona-Vargas, C.C., de Oliveira, K.T., et al. (2018). Susceptibility of Enterococcus faecalis and Propionibacterium acnes to antimicrobial photodynamic therapy. Journal of Photochemistry and Photobiology B: Biology 178, 545-550. doi: https://doi.org/10.1016/j.jphotobiol.2017.11.035.

Deveau, A., Bonito, G., Uehling, J., Paoletti, M., Becker, M., Bindschedler, S., et al. (2018). Bacterial-fungal interactions: ecology, mechanisms and challenges. FEMS Microbiology Reviews 42(3), 335-352. doi: 10.1093/femsre/fuy008.

Dos Santos, R.F., Campos, B.S., Rego Filho, F., Moraes, J.O., Albuquerque, A.L.I., da Silva, M.C.D., et al. (2019). Photodynamic inactivation of S. aureus with a water-soluble curcumin salt and an application to cheese decontamination. Photochem Photobiol Sci 18(11), 27072716. doi: 10.1039/c9pp00196d.

Downum, K.R. (1992). Light-activated plant defence. New Phytologist 122(3), 401-420. doi: 10.1111/j.1469-8137.1992.tb00068.x. 


\section{A new High-Throughput-Screening-assay for Photoantimicrobials}

Dresch, P., D'Aguanno, M.N., Rosam, K., Grienke, U., Rollinger, J.M., and Peintner, U. (2015). Fungal strain matters: colony growth and bioactivity of the European medicinal polypores Fomes fomentarius, Fomitopsis pinicola and Piptoporus betulinus. AMB Express 5(1), 4. doi: 10.1186/s13568-014-0093-0.

Elsworth, C., Gill, M., Giménez, A., M. Milanovic, N., and Raudies, E. (1999). Pigments of fungi. Part 50.1 Structure, biosynthesis and stereochemistry of new dimeric dihydroanthracenones of the phlegmacin type from Cortinarius sinapicolor Cleland. Journal of the Chemical Society, Perkin Transactions 1 (2), 119-126. doi: 10.1039/A808340A.

Espinoza, C., Trigos, Á., and Medina, M.E. (2016). Theoretical Study on the Photosensitizer Mechanism of Phenalenone in Aqueous and Lipid Media. The Journal of Physical Chemistry A 120(31), 6103-6110. doi: 10.1021/acs.jpca.6b03615.

Flors, C., and Nonell, S. (2006). Light and Singlet Oxygen in Plant Defense Against Pathogens: Phototoxic Phenalenone Phytoalexins. Accounts of Chemical Research 39(5), 293-300. doi: 10.1021/ar0402863.

Frey-Klett, P., Burlinson, P., Deveau, A., Barret, M., Tarkka, M., and Sarniguet, A. (2011). BacterialFungal Interactions: Hyphens between Agricultural, Clinical, Environmental, and Food Microbiologists. Microbiology and Molecular Biology Reviews 75(4), 583-609. doi: 10.1128/mmbr.00020-11.

Galstyan, A., Putze, J., and Dobrindt, U. (2018). Gaining Access to Bacteria through (Reversible) Control of Lipophilicity. Chemistry - A European Journal 24(5), 1178-1186. doi: https://doi.org/10.1002/chem.201704562.

Gao, J.-M., Qin, J.-C., Pescitelli, G., Di Pietro, S., Ma, Y.-T., and Zhang, A.-L. (2010). Structure and absolute configuration of toxic polyketide pigments from the fruiting bodies of the fungus Cortinarius rufo-olivaceus. Organic \& Biomolecular Chemistry 8(15), 3543-3551. doi: 10.1039/C002773A.

Gill, M., and Steglich, W. (1987). Pigments of fungi (Macromycetes). Fortschr Chem Org Naturst $51,1-317$.

Hammerle, F., Bingger, I., Pannwitz, A., Magnutzkie, A., Gstir, R., Rutz, A., et al. (2020). Biphyscion - The First Photo-Active Pigment of Mushrooms (Cortinarius uliginosus) Indicates a New Defense Strategy in the Subgenus Dermocyboid Cortinarii and is a Highly Active Photosensitizer Inducing Apoptosis. submitted.

Haukvik, T., Bruzell, E., Kristensen, S., and Tønnesen, H.H. (2009). Photokilling of bacteria by curcumin in different aqueous preparations. Studies on curcumin and curcuminoids XXXVII. Pharmazie 64(10), 666-673.

Hofbauer, C. (1983). Chemotaxonomische Untersuchungen in der Untergattung Phlegmacium.

Hopkins, S.L., Siewert, B., Askes, S.H.C., Veldhuizen, P., Zwier, R., Heger, M., et al. (2016). An in vitro cell irradiation protocol for testing photopharmaceuticals and the effect of blue, green, and red light on human cancer cell lines. Photochemical \& Photobiological Sciences 15(5), 644-653. doi: 10.1039/C5PP00424A.

Hudson, J.B., and Towers, G.H. (1991). Therapeutic potential of plant photosensitizers. Pharmacol Ther 49(3), 181-222. 


\section{A new High-Throughput-Screening-assay for Photoantimicrobials}

Hyde, K.D., Xu, J., Rapior, S., Jeewon, R., Lumyong, S., Niego, A.G.T., et al. (2019). The amazing potential of fungi: 50 ways we can exploit fungi industrially. Fungal Diversity 97(1), 1-136. doi: 10.1007/s13225-019-00430-9.

Katz, S., Backeris, P., Merck, C., Suprun, M., D’Souza, S., Bishop, D.F., et al. (2018). Design and validation of an open-source modular Microplate Photoirradiation System for highthroughput photobiology experiments. PLOS ONE 13(10), e0203597. doi: 10.1371/journal.pone.0203597.

Künzler, M. (2018). How fungi defend themselves against microbial competitors and animal predators. PLOS Pathogens 14(9), e1007184. doi: 10.1371/journal.ppat.1007184.

Lachowicz, J.I., Dalla Torre, G., Cappai, R., Randaccio, E., Nurchi, V.M., Bachor, R., et al. (2020). Metal self-assembly mimosine peptides with enhanced antimicrobial activity: towards a new generation of multitasking chelating agents. Dalton Transactions 49(9), 2862-2879. doi: 10.1039/C9DT04545G.

Lee, I.H., Cho, Y., and Lehrer, R.I. (1997). Effects of $\mathrm{pH}$ and salinity on the antimicrobial properties of clavanins. Infection and Immunity 65(7), 2898-2903.

Lewis, K. (2020). The Science of Antibiotic Discovery. Cell 181(1), 29-45. doi: https://doi.org/10.1016/j.cell.2020.02.056.

Maisch, T. (2015). Resistance in antimicrobial photodynamic inactivation of bacteria. Photochemical \& Photobiological Sciences 14(8), 1518-1526. doi: 10.1039/C5PP00037H.

Merigo, E., Conti, S., Ciociola, T., Manfredi, M., Vescovi, P., and Fornaini, C. (2019). Antimicrobial Photodynamic Therapy Protocols on Streptococcus mutans with Different Combinations of Wavelengths and Photosensitizing Dyes. Bioengineering (Basel) 6(2). doi: 10.3390/bioengineering6020042.

Microbiology, E.C.f.A.S.T.o.t.E.S.o.C., and Diseases, I. (2003). Determination of minimum inhibitory concentrations (MICs) of antibacterial agents by broth dilution. Clinical Microbiology and Infection 9(8), ix-xv. doi: 10.1046/j.1469-0691.2003.00790.x.

Minnock, A., Vernon, D.I., Schofield, J., Griffiths, J., Parish, J.H., and Brown, S.B. (2000). Mechanism of Uptake of a Cationic Water-Soluble Pyridinium Zinc Phthalocyanine across the Outer Membrane of $<\mathrm{em}>$ Escherichia coli $</ \mathrm{em}>$. Antimicrobial Agents and Chemotherapy 44(3), 522-527. doi: 10.1128/aac.44.3.522-527.2000.

Moreno, I., Avendaño-Alejo, M., and Tzonchev, R.I. (2006). Designing light-emitting diode arrays for uniform near-field irradiance. Applied Optics 45(10), 2265-2272. doi: 10.1364/AO.45.002265.

Morici, P., Battisti, A., Tortora, G., Menciassi, A., Checcucci, G., Ghetti, F., et al. (2020). The in vitro Photoinactivation of Helicobacter pylori by a Novel LED-Based Device. Frontiers in Microbiology 11(283). doi: 10.3389/fmicb.2020.00283.

Moser, M. (1972). Die Gattung Dermocybe (Fr.) Wünsche (Die Hautköpfe). Schw.Zeitschrift für Pilzkunde. 83,11. Sondernummer 83,, 153-167.

Mugas, M.L., Calvo, G., Marioni, J., Céspedes, M., Martinez, F., Sáenz, D., et al. (2021). Photodynamic therapy of tumour cells mediated by the natural anthraquinone parietin and blue light. Journal of Photochemistry and Photobiology B: Biology 214, 112089. doi: https://doi.org/10.1016/j.jphotobiol.2020.112089. 


\section{A new High-Throughput-Screening-assay for Photoantimicrobials}

Nielsen, H.K., Garcia, J., Væth, M., and Schlafer, S. (2015). Comparison of Riboflavin and Toluidine Blue $\mathrm{O}$ as Photosensitizers for Photoactivated Disinfection on Endodontic and Periodontal Pathogens In Vitro. PLOS ONE 10(10), e0140720. doi: 10.1371/journal.pone.0140720.

Ogonowska, P., Woźniak, A., Pierański, M., Wasylew, T., Kwiek, P., Brasel, M., et al. (2019). Application and characterization of light-emitting diodes for photodynamic inactivation of bacteria. Lighting Research \& Technology 51(4), 612-624. doi: 10.1177/1477153518781478.

Pieslinger, A., Plaetzer, K., Oberdanner, C.B., Berlanda, J., Mair, H., Krammer, B., et al. (2006). Characterization of a simple and homogeneous irradiation device based on light-emitting diodes: A possible low-cost supplement to conventional light sources for photodynamic treatment. Medical Laser Application 21(4), 277-283. doi: 10.1016/j.mla.2006.07.004.

Quintanar, L.F.H., Silva, F.Y.L., Bustos, D.A.F., Navarro, J.S., Vázquez, J.M.d.L.R., Brodin, P.N., et al. (2016). In Vitro Photoirradiation System for Simultaneous Irradiation with Different Light Doses at a Fixed Temperature. Photomedicine and Laser Surgery 34(3), 108-115. doi: 10.1089/pho.2015.4030.

Reifegerste, F., and Lienig, J. (2008). Modelling of the Temperature and Current Dependence of LED Spectra. Journal of Light \& Visual Environment 32(3), 288-294. doi: $10.2150 /$ jlve.32.288.

Schmidt, R., Tanielian, C., Dunsbach, R., and Wolff, C. (1994). Phenalenone, a universal reference compound for the determination of quantum yields of singlet oxygen $\mathrm{O} 2(1 \Delta \mathrm{g})$ sensitization. Journal of Photochemistry and Photobiology A: Chemistry 79(1), 11-17. doi: https://doi.org/10.1016/1010-6030(93)03746-4.

Schubert, E.F. (2006). Light-Emitting Diodes (Second Edition, 2006). E. Fred Schubert.

Siewert, B. (2021). Does the chemistry of fungal pigments demand the existence of photoactivated defense strategies in basidiomycetes? Photochemical \& Photobiological Sciences. doi: 10.1007/s43630-021-00034-w.

Siewert, B., and Stuppner, H. (2019). The photoactivity of natural products - An overlooked potential of phytomedicines? Phytomedicine 60, 152985. doi: 10.1016/j.phymed.2019.152985.

Siewert, B., Vrabl, P., Hammerle, F., Bingger, I., and Stuppner, H. (2019). A convenient workflow to spot photosensitizers revealed photo-activity in basidiomycetes. RSC Advances 9(8), 45454552. doi: 10.1039/C8RA10181G.

Supronowicz, R., and Fryc, I. (Year). "The LED spectral power distribution modelled by different functions - how spectral matching quality affected computed LED color parameters", in: 2019 Second Balkan Junior Conference on Lighting (Balkan Light Junior)), 1-4.

Tingstad, L., Gjerde, I., Dahlberg, A., and Grytnes, J.A. (2017). The influence of spatial scales on Red List composition: Forest species in Fennoscandia. Global Ecology and Conservation 11, 247-297. doi: https://doi.org/10.1016/j.gecco.2017.07.005.

Wainwright, M. (2009). Photoantimicrobials - So what's stopping us? Photodiagnosis and Photodynamic Therapy 6(3), 167-169. doi: https://doi.org/10.1016/j.pdpdt.2009.10.007.

Weinstein, M.P., and Lewis, J.S., 2nd (2020). The Clinical and Laboratory Standards Institute Subcommittee on Antimicrobial Susceptibility Testing: Background, Organization, Functions, and Processes. J Clin Microbiol 58(3). doi: 10.1128/jcm.01864-19. 


\section{A new High-Throughput-Screening-assay for Photoantimicrobials}

Wiegand, C., Abel, M., Ruth, P., Elsner, P., and Hipler, U.C. (2015). pH Influence on Antibacterial Efficacy of Common Antiseptic Substances. Skin Pharmacology and Physiology 28(3), 147158. doi: $10.1159 / 000367632$.

Wiegand, I., Hilpert, K., and Hancock, R.E.W. (2008). Agar and broth dilution methods to determine the minimal inhibitory concentration (MIC) of antimicrobial substances. Nature Protocols 3 , 163. doi: 10.1038/nprot.2007.521.

Wood, D. (1994). Optoelectronic Semiconductor Devices. Prentice Hall.

Wozniak, A., and Grinholc, M. (2018). Combined Antimicrobial Activity of Photodynamic Inactivation and Antimicrobials-State of the Art. Frontiers in Microbiology 9(930). doi: 10.3389/fmicb.2018.00930.

Zhang, A.L., Qin, J.C., Bai, M.-S., Gao, J.M., Zhang, Y.M., Yang, S.X., et al. (2009). Rufoolivacin $\mathrm{B}$, a novel polyketide pigment from the fruiting bodies of the fungus Cortinarius rufoolivaceus (basidiomycetes). Chinese Chemical Letters 20(11), 1324-1326. doi: https://doi.org/10.1016/j.cclet.2009.05.021. 